\section{ONOMAREDIN}

Revista semestral de lingüística, filología y traducción
PONTIFICIA UNIVERSIDAD CATÓLICA DE CHILE CATOLICA DE CHILE
FACULTAD DE LETRAS

\title{
Revisiting field: Specialized knowledge in secondary school science and humanities discourse
}

\author{
J. R. Martin \\ The University of Sydney, Australia \\ Martin Centre for Appliable Linguistics, \\ Shanghai Jiao Tong University, China
}

Número especial
ONOMÁZEIN Número especial LSF y TCL sobre educación y conocimiento (2017): 111-148 DOI: 10.7764/onomazein.sfl.05

\section{(C) $\underset{\text { BY }}{ } \bigodot_{\mathrm{ND}}$}

J. R. Martin: Martin Centre for Appliable Linguistics, Shanghai Jiao Tong University, China / Department of Linguistics, The University of Sydney, Australia. | Correo electrónico: james.martin@sydney.edu.au 


\section{Abstract}

This paper revisits the register variable field in systemic functional linguistics (SFL), in relation to the concept of 'semantic density' in Legitimation Code Theory (LCT). Re-interpretations of the specialized meaning construing disciplinarity are proposed, from the perspective of the ideational, interpersonal and textual metafunctions-highlighting technicality, iconization and aggregation respectively. The term 'mass' is suggested as a cover term for these resources. The paper contributes to an ongoing dialogue between SFL and LCT in relation to research on secondary school history and biology discourse in Australian schools, an increasingly productive exercise in transdisciplinary research.

Keywords: Semantic density; technicality; field; systemic functional linguistics; Legitimation Code Theory. 


\section{Dialogue}

Over the past decade, dialogue between Systemic Functional Linguistics (hereafter SFL) and Legitimation Code Theory (hereafter LCT) about the nature of knowledge (documented in Christie \& Martin, 2007; Christie \& Maton, 2011; Maton et al., 2016) has renewed interest among the linguists involved in the register variable field (e.g. Martin, 2007; Martin et al., 2010). More recently, as part of interdisciplinary projects focusing on knowledge-building in secondary school history and science lessons (see Martin and Maton, this issue), Maton's work on 'semantic density' (Maton, 2011, 2014) has rekindled interest in the construal of specialized knowledge in uncommon sense discourse. For Maton, semantic density (SD)

refers to the degree of condensation of meaning within sociocultural practices (symbols, terms, concepts, phrases, expressions, gestures, clothing, etc). Semantic density may be relatively stronger (+) or weaker (-) along a continuum of strengths. The stronger the semantic density (SD+), the more meanings are condensed within practices; the weaker the semantic density (SD-), the less meanings are condensed (Maton, 2014: 129).

And critically, as we will explore below, the meanings involved 'may be from formal definitions, empirical descriptions or feelings, political sensibilities, taste, values, morals, affiliations, and so forth' (Maton, 2013: 11).

Maton's concern with condensation of meaning (see also the two papers by Maton \& Doran, in this issue) naturally invites a response from functional linguists in relation to their work on technicality and the distillation of meaning in academic and professional discourses of various kinds. Key references on this work include Rose et al. (1992), Halliday \& Martin (1993), Christie \& Martin (1997), Martin \& Veel (1998), Halliday (2004), Wignell (2007) and Martin (2012). Much of this work explored aspects of Martin's (e.g. 1992) model of field, with field characterized as a set of activity sequences oriented to some global institutional purpose, alongside the taxonomies of participants involved in these sequences (organized by both classification and composition). One important variable in this work was the degree of technicality deployed in a particular field, with technicality explored as a process of distillation-a process whereby meaning is both condensed and reconstituted in lexis construing uncommon sense knowledge of the world.

\section{Field}

In SFL meanings are explored from several different perspectives. These include the level of abstraction at which analysis is undertaken (i.e. phonology/graphology, lexicogrammar, discourse semantics, register and genre in Martin \& Rose, 2007, 2008) and the type of meaning involved (i.e. ideational, interpersonal, textual). In the Martinian register of SFL adopted here 
context is modelled as register and genre, which are treated as abstract levels of meaning. A schematic outline of these perspectives is presented as Figure 1.

\section{FIGURE 1}

The intersection of stratification and metafunction in SFL (viewing diagonally from top to bottom the co-tangential circles represent genre, register, discourse semantics, lexicogrammar and phonology/graphology)

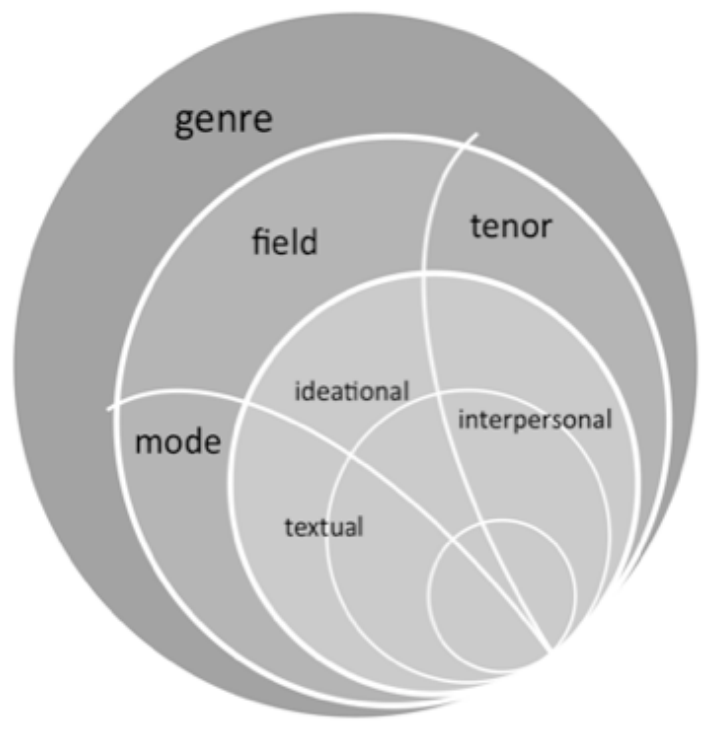

As introduced above, Martin (e.g. 1992) treats field as involving a set of activity sequences which work together to enact one or other walks of life (in the home, at work, at prayer, at play etc.). Each field additionally involves specialized taxonomies of the people, places and things involved in these activities, organized by classification (type and sub-type relations) and composition (whole and part relations). These people, places and things, whether abstract or concrete, may in addition be graded in relation to one another in arrays (e.g. numerical systems, the periodic table of chemical elements, professional ranks such as Field marshal, General, Lieutenant general, Major general etc., or measurement scales such as inch, foot, yard, chain, furlong, mile).

In the penultimate chapter of Martin \& Rose (2008) a multimodal text concerning mulga trees from a secondary school geography textbook (Scott \& Robinson, 1993) is analysed. In this textbook words and pictures cooperate to build knowledge of Australian desert environments and their fauna and flora (touched upon in Martin, 2013a). Two pages further on the textbook moves from discussion of mulga plains to spinifex plains. The main bush found there is commonly referred to as spinifex (although botanically it is Triodia species, not Spinifex species), and even more commonly as hummock grass (because of its mound-like shape when young) or procupine grass (because of its sharp pointed blades). Compositionally speaking we can distinguish the plant's roots (very deep), stem (full of resin), blades (curled), flowers and seeds (as sketched out in Figure 2). 


\section{FIGURE 2}

Composition of a spinifex bush

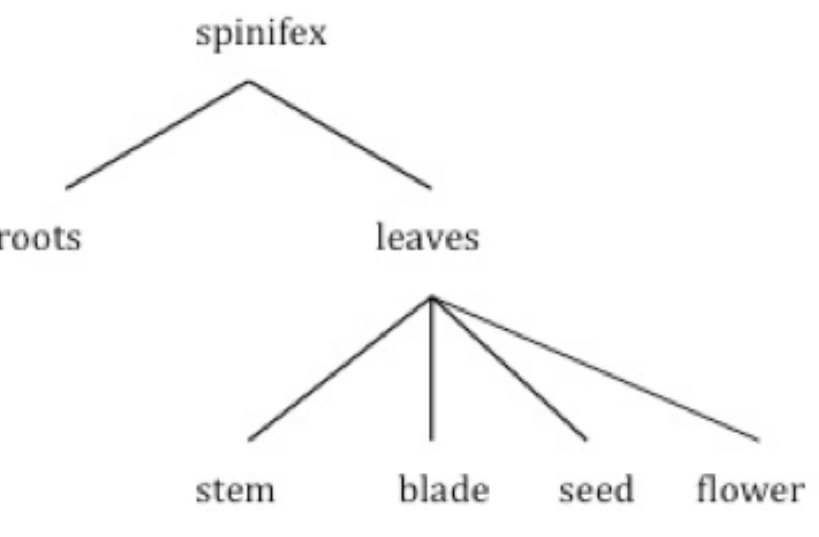

The desert environments this species inhabits, the spinifex plains, are construed in the textbook through classification (using their flora and fauna, fertility and rainfall as criteria) -as desert ranges \& rocky outcrops, plains or rivers, and if plains, then as mulga plains, spinifex plains or saltbush \& blue bush plains. By intersecting this classification of arid lands with a classification of the living things found there, we arrive at a geographic perspective on the kind of thing spinifex is, as outlined in Figure 3 below (where square brackets mean 'or' and curly brackets 'and'). The crucial point I am making in Figures 2 and 3 here is that from the perspective of the field of physical geography, simply recognising a spinifex bush, as a visitor to central Australia or in a photograph, is not enough; in addition, its uncommon sense composition and uncommon sense classification are central to its meaning in this field.

Beyond this the spinifex bush is involved in a number of activity sequences which are fundamental to its survival in its desert environment (for the explanation genres mounting these sequences, see Unsworth, 1997a, b, c; Veel, 1992). There are processes of transpiration and photosynthesis to consider, including the spinifex bush's adaption for these in its desert environment (the fact that each blade of this grass has its own root which penetrates three or more meters into the soil for example, or the curled leaves which curtail water loss but are annoyingly painful for the humans which run into them). And turning from day time to life time, we can consider its life cycle-moving from its generation as a young hummock, to a mature clump (hollowing out with a dead centre as its grows outwards and thereby creating a favorite sleeping spot for kangaroos), to its loss of foliage when it burns intensely in fire, to its regeneration from its roots (or fire-induced germination from seeds). An outline of this cycle is presented as Figure 3.

1 N. Mrgh/Shutterstick.com. Available at: http://www.britannica.com/EBchecked/media/168493/ Great-Victoria-Desert-Australia, date of retrieval: December 29th, 2014. 


\section{FIGURE 3}

Physical geography classification of spinifex bush (flora $x$ environment) ${ }^{1}$

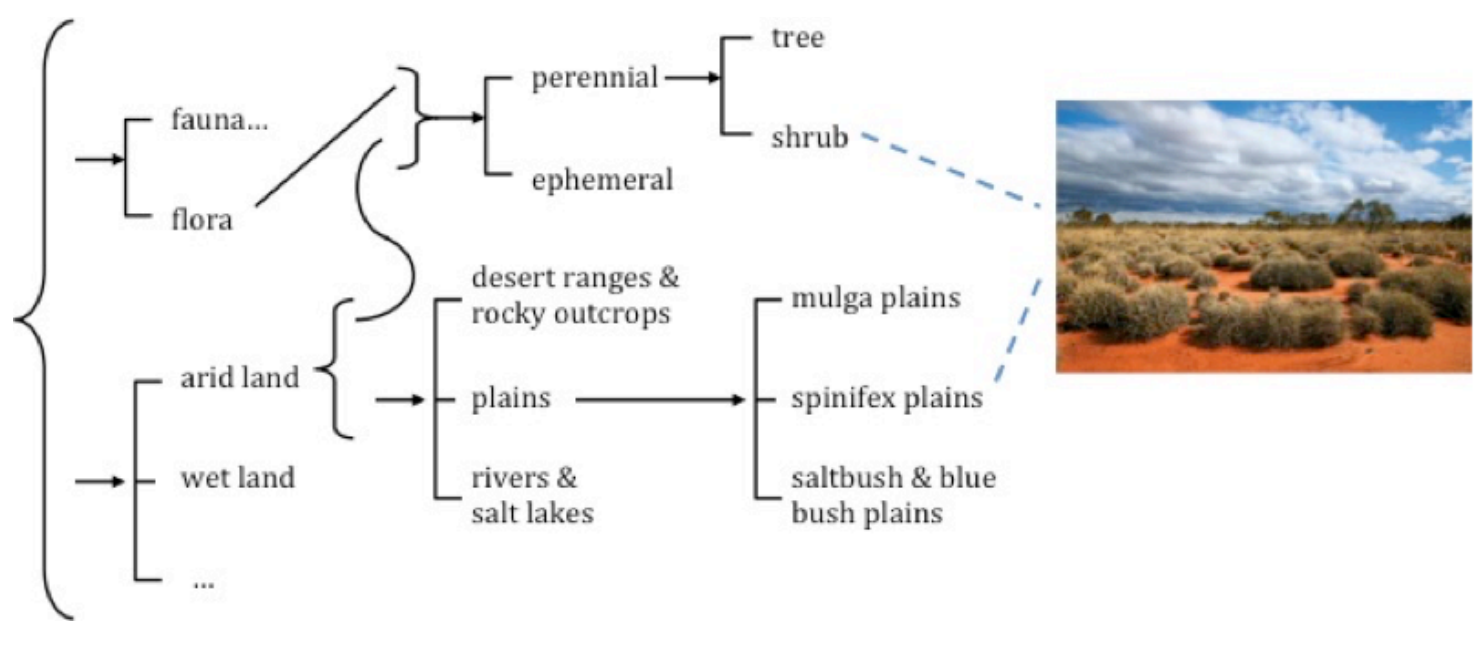

\section{FIGURE 4}

Life cycle of the spinifex (Scott \& Robinson, 1993: 25)

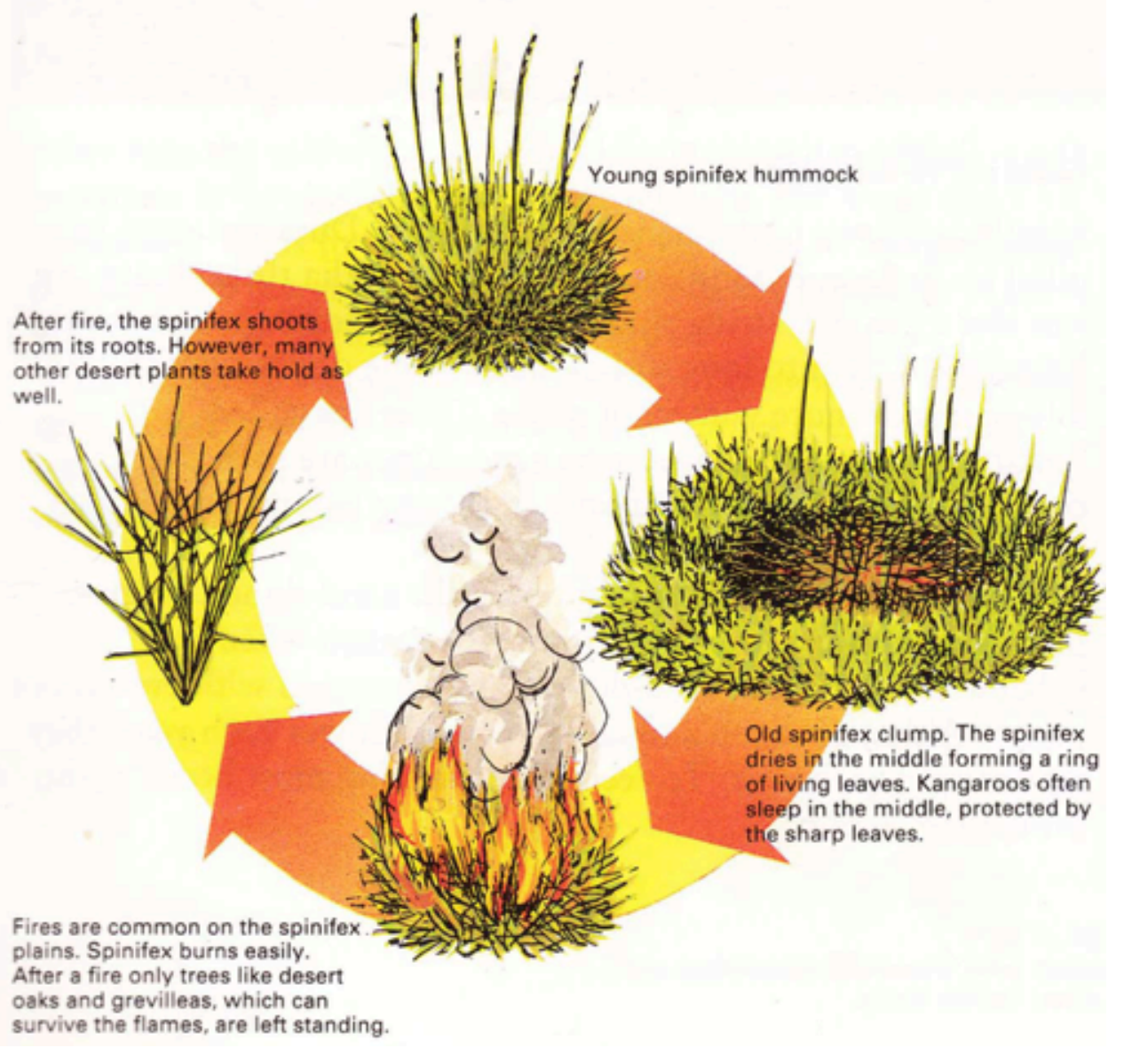


From the perspective of Legitimation Code Theory (LCT) the strength of the 'semantic density' of the entity spinifex (the number of meanings condensed by the term), as understood in physical geography, includes its 'valeur' in the composition and classification taxonomies exemplified above, alongside the role it plays in any sequences in which it is involved (see Maton, 2014; papers by Maton \& Doran, this issue). There is thus much more to the meaning of the term than a simple definition affords (Halliday \& Martin, 1993; Martin, 1989; Wignell et al., 1990)-relatively strong semantic density (conceived in terms of the number of semantic relations in play) is involved as well.

\section{Horizontal discourse}

Bernstein (2000: 157) distinguishes ‘horizontal discourse' from 'vertical discourse'. He characterizes a horizontal discourse as entailing

a set of strategies which are local, segmentally organized, context specific and dependent, for maximising encounters with persons and habitats... This form has a group of well-known features: it is likely to be oral, local, context dependent and specific, tacit, multi-layered and contradictory across but not within contexts.

In terms of Martin's typology of common sense and uncommon sense fields (1992: 539), this type of discourse typically involves oral transmission-combining ostensive definition of entities in the sensuous environment (by naming while pointing to them) with joint participation in activity sequences (where elders play a guiding role until satisfactory performance is developed); this kind of learning by 'doing with' in the home before schooling is well documented in the SFL language development studies, by Halliday (e.g. 1975, 2003) and by Painter (e.g. 1984, 1999, 2003).

\subsection{Everyday reality (common sense fields)}

As far as the entities of everyday life are concerned, the well-known children's song 'Head, shoulders, knees and toes' provides an exemplary illustration of the nature of common sense fields. One version of the lyrics, among many local variations, is provided as Text 1 below. As the song is sung, participants touch the relevant body part with both hands, speeding up the singing of the verses until their gestures can't keep up. The verses canvas the relevant parts of a pre-school child's body as far as domestic needs are concerned, building up as they do a common sense part-whole (compositional) taxonomy of body parts.

[1] Head and shoulders knees and toes Knees and toes Head and shoulders knees and toes 
Knees and toes

And eyes and ears

And mouth and nose

Head and shoulders knees and toes

Knees and toes

Feet and tummies arms and chins

Arms and chins

Feet and tummies arms and chins

Arms and chins

And eyes and ears

And mouth and shins

Feet and tummies arms and chins

Arms and chins

Composition taxonomies of this kind are relevant to various domestic activities including washing, dressing, eating and so on and can be drawn on as required when learning with an adult guide or more capable peer. The children's picture book Sunshine (1981) images one sequence of this kind (Figure 1 ), as a young girl gets herself ready for school-now doing on her own what for several years her parents had to help her with (with tying shoe laces or buckling shoes as perhaps the penultimate stage in contemporary western versions of this particular developmental process, followed later on, for males at least, with learning to tie a tie).

\section{FIGURE 5}

Getting dressed (Omerod, 1981)
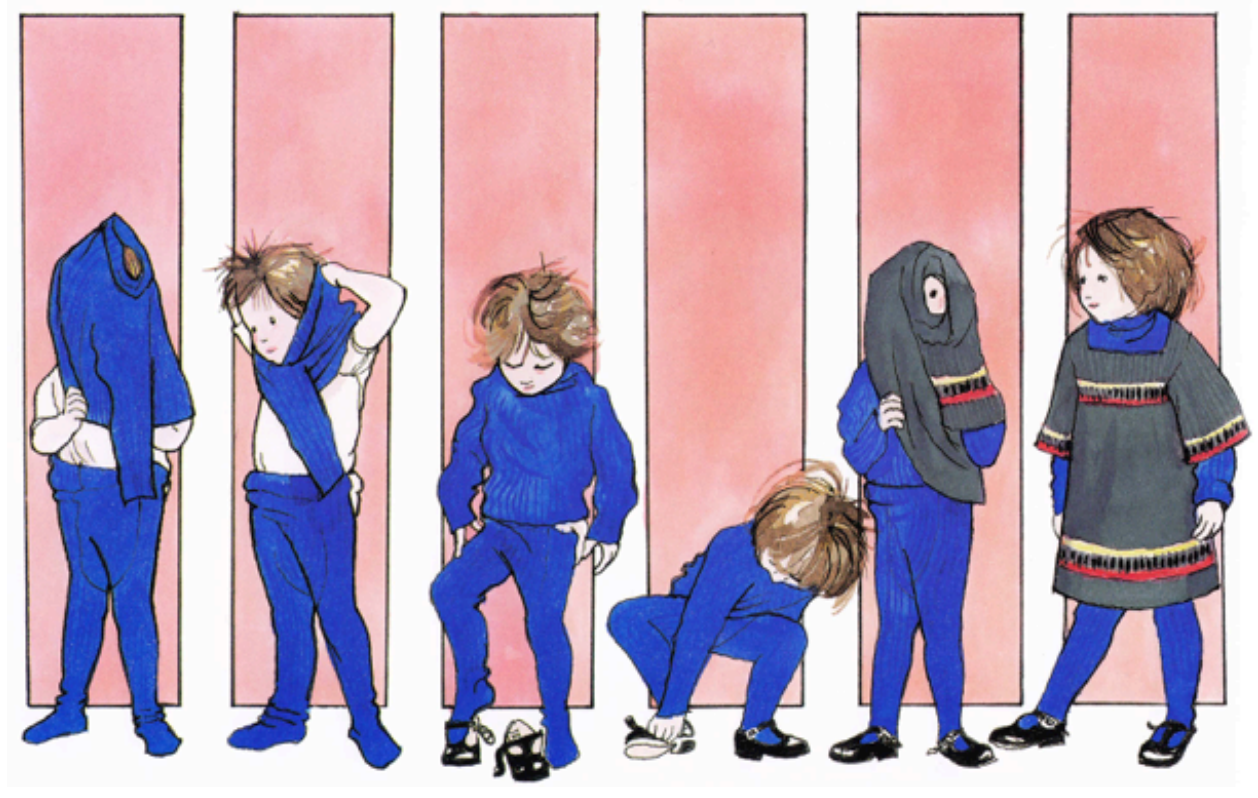


\subsection{Extended reality (specialized fields)}

Ostensive definition and learning by 'doing with' also characterize a range of fields that Martin (1992: 542-542) characterizes as specialized² (cf. Halliday \& Martin, 1993; White, 1998). These involve what we might think of as the extended reality of trades, crafts, hobbies, sports and recreational activities. These fields typically involve more elaborated taxonomies than everyday ones, and activity sequences with more tiers of action.

By way of illustrating a more elaborated taxonomy, consider the nomenclature for muscles in body building. In this specialized field, what in everyday discourse we simply refer to as an arm has to be broken down into its musculature. We have biceps, triceps and forearms to consider. For biceps we have to further consider the Brachialis and Biceps Brachii muscle groups, further dividing Biceps Brachii into long head and short head muscles; and triceps (Triceps Brachii) are divided into long head, lateral head and media head muscles. These taxonomic relations are outlined below (I won't pursue the musculature of forearms here).

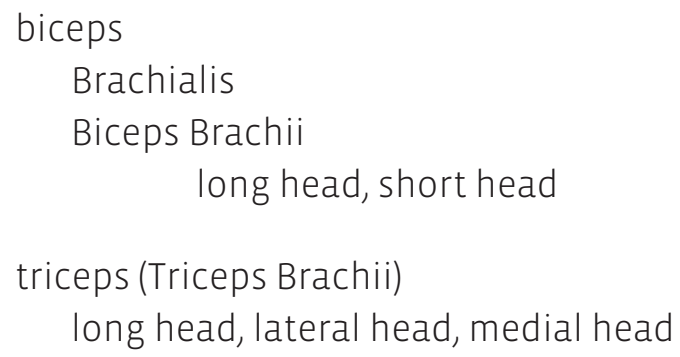

This elaborated nomenclature, alongside taxonomies for what are colloquially referred to as pecs, traps, delts, lats, quads, abs and so on is fundamental to body building in relation to weight training and the body shape that training is designed to produce. As with everyday discourse, the entities named are part of sensuous experience-both felt and observed during training and posed in competition. Making visible each muscle group is essential in this field.

By way of illustrating multi-tired activity, let's consider tennis. In this sport activity sequencing involves a match, with each match typically involving 1 , 3 or 5 sets, with each set involving 6 or more games (with a maximum of 13 games if a tie-break game is played at 6 all), with each game involving 4 or more points (except for a tie-break set which involves a

2 Note that I am using the terms 'specialized' and 'technical' as opposed in order to distinguish the extended domains of horizontal discourse such as trades, crafts, hobbies, sports and other recreational activities (best understood as 'discursos técnicos' in Spanish, see glossary in this Special Issue) from uncommon sense domains of vertical discourse (best understood as 'discursos especializados' in Spanish); Bernstein uses the term 'specialized' more inclusively, to include what I call technical discourse. 
minimum of 7 points), with each point involving one or more shots. Shots can be divided into serve, groundstroke, volley and overhead, the latter three of which can be cross-classified as forehand or backhand. Groundstrokes can be further divided into drive, half-volley, drop shot and lob, all of which can be cross-classified as played flat or with spin, and if with spin, then as slice or top-spin.

shot:

serve, groundstroke, volley, overhead

[forehand/backhand (except serve)]

groundstroke:

[flat/spin: topspin/slice]

drive, half-volley, drop shot, lob

Keeping this classification in mind, each shot can be broken down into a further tier of sequencing. A serve for example involves preparation, stroke and follow through; and the preparation can be broken down into taking position, grip (for both ball and racquet) and concentration, with the stroke itself involving the ball toss and coincident swing consummated in hitting the ball. Without pushing through to the finer points of how exactly to make contact with the ball (elevation, racquet angle and trajectory, ball toss position, body torque etc.) we have established 7 tiers of activity (i.e. match, set, game, point, shot, stroke, hit), many more tiers than need to be managed in everyday sequences-which is why coaching rather than uninformed parenting is required to train a player well.

White (1998) coins the term 'technocality' to refer to the elaborated taxonomies and activity sequences at play in specialized fields. The term usefully calls to mind the technology involved in mechanized fields, where a prolonged apprenticeship is involved in managing machines and their operations. In fields of this kind we often find labelled diagrams outlining relevant composition taxonomies and flow charts imaging relevant tiers of activity (cf. Rose et al., 1992 on the discourse of science industry). As White notes, specialized fields often feature acronyms which condense Classifiern Thing complexes into more manageable short-hand terms (e.g. RAM for 'random access memory', or ROM for 'read only memory' in computing). While the taxonomic import of such terms may be lost on lay users, their relative transparency makes them easy to unpack for specialists in a field (thereby enhancing their utility).

In general terms then, although they are learned in the same way as everyday domestic fields, specialized fields can be distinguished in several respects. Their elaborated taxonomies and multi-tiered activity sequences mean that they are learned through mentoring, apprenticeship, training, coaching and initiating rather than parenting. This hands-on transmission means that although the activities involved sink beneath consciousness once mastered, they can be recovered and brought to consciousness as required. Playing a tennis shot for example 
is something we enact as automatically as possible during a point, so we can concentrate on strategic aspects of play; but if a shot is breaking down, we bring the relevant tier of activity back to consciousness and try to adjust the shot accordingly (e.g. adjusting our grip, our ball toss, our wrist action etc. on serve). We can also note here the tendency of specialized fields to complement technical ones (Bernstein's 'vertical discourse') in regions of practice-consider for example the relation of mechanics to engineers, of builders to architects, of trainers to sports physiologists, of lab assistants to scientists, of nurses to doctors, of detectives to forensic scientists, of accountants to economists, of Justices of the Peace to lawyers and so on. Increasingly, in post-Fordist neo-liberal economies, the complementarity of specialized and technical discourses is becoming more weakly classified. There is an increasing tendency for written documentation of specialized taxonomies (in multimodal report genres) and activity sequences (in multimodal procedure and protocol genres); and this means that specialized fields increasingly involve at least some institutionalized learning (technical college, sports academy, boot camp etc.). The specialized knowledge that once relied on oral transmission in a region of practice now depends at least in part on functional literacy in programmed learning (Rose et al., 1992).

\section{Vertical discourse}

As noted above, Bernstein (2000: 157) distinguishes horizontal discourse from vertical discourse. He characterizes vertical discourse as taking 'the form of a coherent, explicit and systematically principled structure, hierarchically organized as in the sciences' or 'the form of a series of specialized languages with specialized modes of interrogation and specialized criteria for the production and circulation of texts as in the social sciences and humanities.'

In terms of Martin's (1992: 544) typology of common sense and uncommon sense fields, this type of discourse typically involves written transmission in institutionalized contexts of learning, religious or secular; advanced literacy is crucial. Bernstein's division between the sciences and the social sciences and humanities echoes work by Martin and his colleagues (e.g. Christie \& Martin, 1997; Martin, 2012) on degrees of technicality and abstraction as syndromes of meaning differentiating vertical discourses.

Elaborating this framework Bernstein characterizes the more scientific discourses as 'hierarchical knowledge structures' which evolve by attempting 'to create very general propositions and theories, which integrate knowledge at lower levels...' and in this way show 'underlying uniformities across an expanding range of apparently different phenomena' (2000: 161, 162). These he opposes to 'horizontal knowledge structures' which tend to evolve via the introduction of a new 'language' which constructs a 'fresh perspective, a new set of questions, a new set of connections, and an apparently new problematic, and most importantly a new set of speakers' (2000: 162). As an example from social science we might propose the 
diverse models of language proposed in functional linguistics (e.g. role and reference grammar, Dik's functional grammar and systemic functional grammar as reviewed in Butler 2003).

As is well known SFL generally adopts a tri-nocular perspective on meaning, with ideational meaning construing reality, interpersonal meaning enacting social relations and textual meaning organising these construals and enactments into waves of information flow. In this paper I draw on this metafunctional cartography to reconsider the knowledge construed in vertical discourse from the perspectives of ideational, interpersonal and textual meaning. We'll start our discussion of uncommon sense fields by focusing on ideational meaning, since this is where so many discussions of field and technicality in SFL begin (and end)-before extending our perspective by moving on to a consideration of interpersonal and textual dimensions of knowledge building in vertical discourse.

\subsection{Alter-reality (technicality)}

Tim Flannery, an acclaimed Australian biologist and environmentalist celebrates the style of Glickson's 2014 Evolution of the Atmosphere as follows:

[2] 'Elevated $\mathrm{CO}_{2}$ led to acidification of ocean water from $\sim 8.2$ to $\sim 7.5 \mathrm{pH}$ and the extinction of $35-50 \%$ of benthic formaminifera over $\sim 1000$ years.'

This neatly summarizes countless hours of research, and describes an Earth whose atmosphere was so supercharged by greenhouse gases that the acidifying oceans led to mass extinctions, ecosystem crises and an ocean floor corroded red with acid. Only when conditions are reduced to such simple terms can meaningful comparisons between various crises in Earth's history be made (Flannery, T 2014: 44).

In particular he admires the concise expression afforded by Glickson's technicality, which includes chemical and mathematical symbols $\left(\mathrm{CO}_{2}, \sim 8.2, \sim 7.5 \mathrm{pH}, 35-50 \%, \sim 1000\right)$ and technical terms referring to both entities (benthic formaminifera) and processes (acidification, extinction). Clearly the knowledge condensed in these symbols and terms cannot be learned by simply pointing out concrete objects in the world and jointly undertaking physical activity; the knowledge Glickson and Flannery are sharing here depends on years of training in school and university settings, drawing heavily on written texts, where vertical discourse is stored-supplemented along the way by the text mediating spoken discourse of lectures and seminars, and exemplificatory and exploratory interactive discourse in laboratories and in the field.

As part of this training scientists develop alternative ways of classifying and composing the world and explaining change along many scales of time. In terms of classification, they learn for example that forminifera (literally 'hole bearers') are single-celled amoebid protists, 
thereby arranging them in a still contested classification of their place among the living things in the world; and they learn that the Classifer benthic places the forminifera in question as living at the bottom of a body of water, on or just under sediment. In terms of composition they learn that amoeboid protists feature shells (more technically tests), commonly made of calcium carbonate $\left(\mathrm{C}_{\mathrm{a}} \mathrm{CO}_{3}\right)$, and also pseudopodia (literally 'false feet') which extend and retract and are used for movement and nutrition. Note that an accessible definition like the one that follows distils just some of this knowledge:

[3] Benthic foraminifera are a phylum of amoeboid protists characterized by their thin pseudopodia that form an external net for catching food and an external shell and living on or within seafloor sediment.

Definitions in science are simply a guide to the uncommon sense classification, composition and implication sequences relating phenomena to one another; they by no means exhaust the field relations involved.

Turning to processes, ocean acidification can be defined as the ongoing decrease in the $\mathrm{pH}$ of the Earth's oceans, due to the uptake of carbon dioxide $\left(\mathrm{CO}_{2}\right)$ from the atmosphere. This implicates a measure of the acidity or basicity of a liquid $(\mathrm{pH})$, with pure water taken as a base line of 7 (solutions less than 7 are acidic, more than 7 as basic or alkaline). Chemically speaking, what is measured is the concentration of hydronium ions $\left(\mathrm{H}^{+}\right)$. And the definition flags a chemical process whereby carbon dioxide $\left(\mathrm{CO}_{2}\right)$ reacts with water $\left(\mathrm{H}_{2} \mathrm{O}\right)$ to form carbonic acid $\left(\mathrm{H}_{2} \mathrm{CO}_{3}\right)$. Some of these molecules in turn react with water molecules to produce a bicarbonate ion and a hydronium ion, thereby increasing acidity. I won't take time to consider the classification and composition taxonomies and elemental arrays organising the chemical entities at play here; their symbolism makes aspects of this clear. Suffice it to say that technicality is as critical to processes in science as it is to entities. Alter-reality construes a world of both uncommon sense entities and the uncommon sense sequences in which they are involved (termed implication sequences to highlight the logical 'if/then' unfolding of such sequences in Martin, 1990).

In many knowledge structures the verbal relations reviewed thus far are supplemented by symbolic and imagic modalities that afford a 'hyper-technicality' further extending the vertical discourse of these disciplines. Doran (2016) explores the use of mathematics and images (graphs in particular) to extend physics discourse along these lines. Here l'll draw on an example from linguistics to illustrate the function of symbolization and the alter-grammar symbolism affords.

A fragment of the grammar of English MOOD is presented as Figure 6 (following notation reviewed in Martin 2013b). The system network contains a number of technical terms (known in SFL as features) for classes of clause: major, indicative, imperative, declarative, informative, 
declarative, exclamative, interrogative, polar, wh, positive and negative. In addition it contains a number of symbols for the structural implications of these features: P, C, A, Wh-, S, F, MA, Whex and neg. Note that these are symbols, not abbreviations for verbalized terms. Wh- is lexicalized through the interrogative words who, what, which, where, when, why and how, Whex through both what $a^{\wedge}$... (e.g. What a fool he is!) and how^... (e.g. How silly she was!) and neg through not/n't, hardly, scarcely etc.

\section{FIGURE 6}

A fragment of English MOOD (Martin, 2013b)

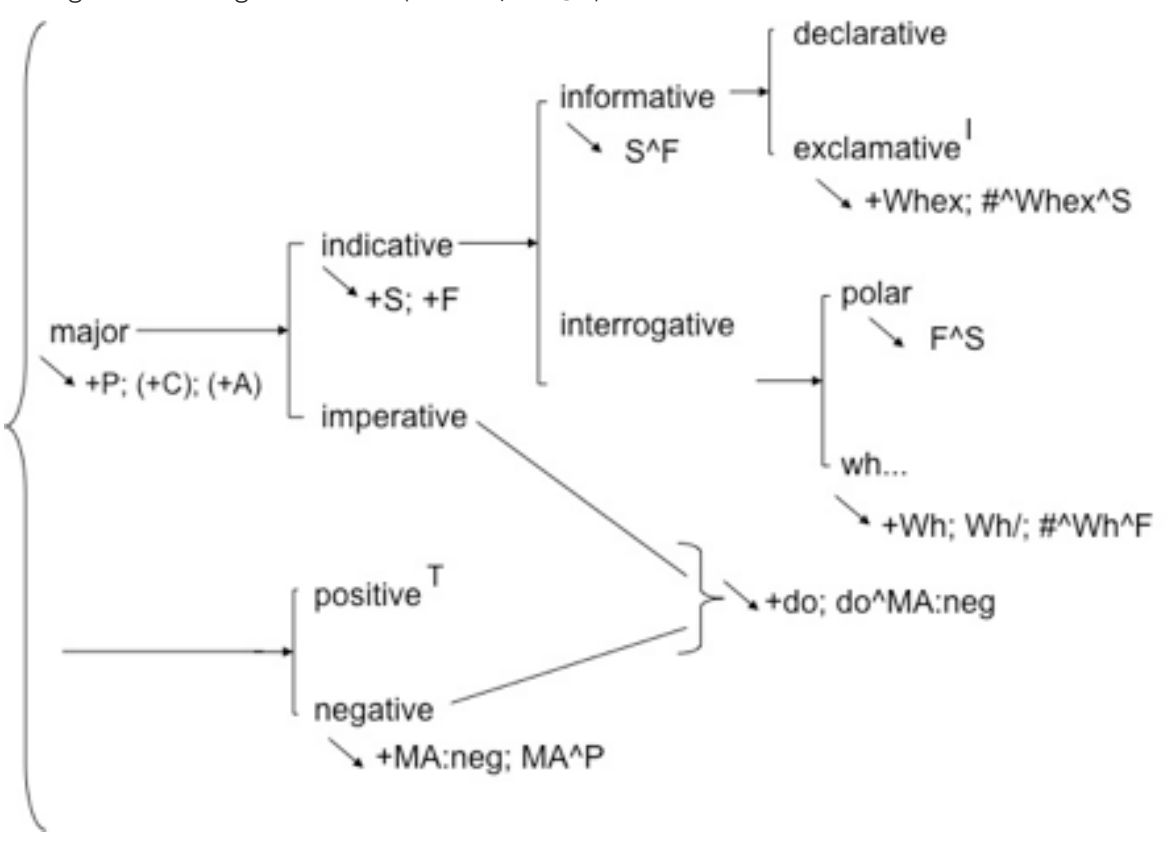

The technical terms and the symbols are related to one another in the network by the downward slanting arrow, which formalizes the axial relation of system (paradigmatic relations) to structure (syntagmatic relations) in SFL. This relation takes us beyond the taxonomy, array and sequence relations introduced for field above. Doran (personal communication) has suggested the term 'implication complex' for field relations of this kind.

In addition to this implication complexing (axis) the system network formalizes a hypertechnical 'syntax' that relates symbols logically to one another. This is perhaps easier to observe if I remove the technical terms and symbols from the diagram as in Figure 7 . The right-facing square brackets with horizontal arrows leading into them relate features as alternatives in systems (logical 'or'); and the right-facing brace relates systems as cross-classifying one another (logical 'and'). Turning to the symbols, the + before a symbol for example indicates that the symbol is present in a structure; and \#^ indicates that the symbol comes first in its structure. I won't take time here to outline this alter-grammar in more detail; a full discussion 
is presented in Martin (2013b). My point here is that the hyper-technicality of the symbols and the specialized syntax relating symbols succinctly formalizes knowledge that takes much longer to construe in verbal discourse.

\section{FIGURE 7}

The hyper-syntax of the MOOD network in Figure 6

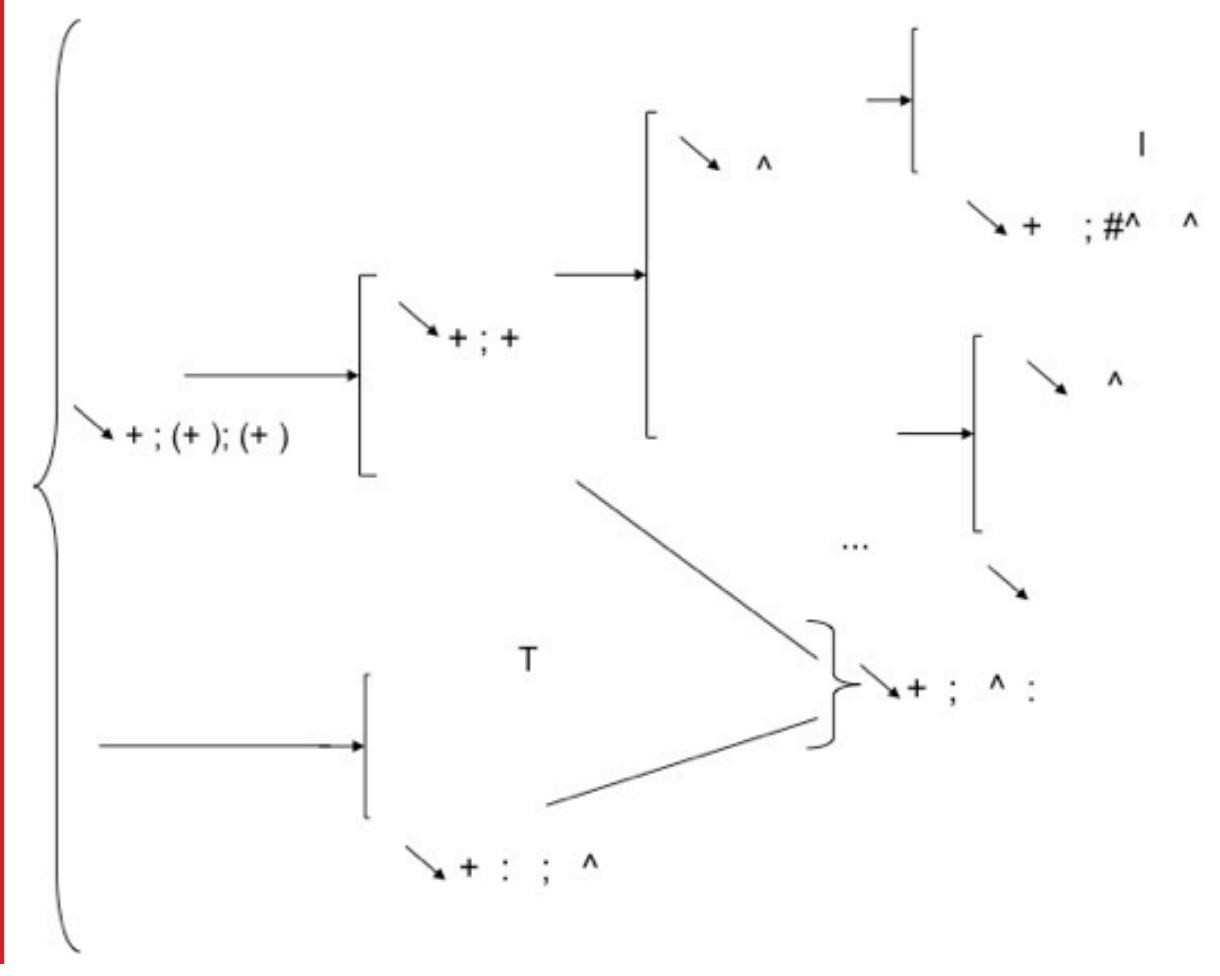

The succinctness of this formalization, as an 'eyeful' we night say, in addition facilitates consideration of degrees of interdependency among terms and symbols that would be very awkward to conceive using verbal language alone. As highlighted in Figure 8, we can observe a number of interdependencies among features in the network. The ${ }^{1 / T}$ superscript notation for example ensures that exclamative clauses are positive but not negative (What a fool he is!, *What a fool he isn't!). The left-facing brace takes into account the fact that negative imperative clauses, but not positive imperative ones, require the insertion of do (Take care, *Don't worry). And the arrows leading from technical terms to the choice of alternative features shows the dependency of certain choices on others; only informative clauses can be exclamative or declarative, not interrogative or imperative ones (What a fool he is!, */s he what a fool!, *Be what a fool!). It was precisely interdependencies of this order that led Halliday (e.g. 1969) to the 'discovery' of metafunctions - namely the idea that clause systems in English grammar tend to fall into three main groups according to the degree of interdependency among features, which he referred to aS TRANSITIVITY, MOOD and THEME (later extended and generalized as ideational, interpersonal and textual strands of meaning across ranks and strata, and later modalities. 
SFL's hyper-technicality can thus be seen to lead to the derivation of new concepts which the lexicogrammar of verbal language would not afford. Doran (this volume) outlines the way in which mathematics works in a comparable way for the generation of new knowledge in phsysics - where it arguably plays a far more instrumental role than hyper-technicality in linguistics (in the interests of both quantification and the derivation of new concepts).

\section{FIGURE 8}

Interdependency among MOOD systems in relation to the conept of metafunction

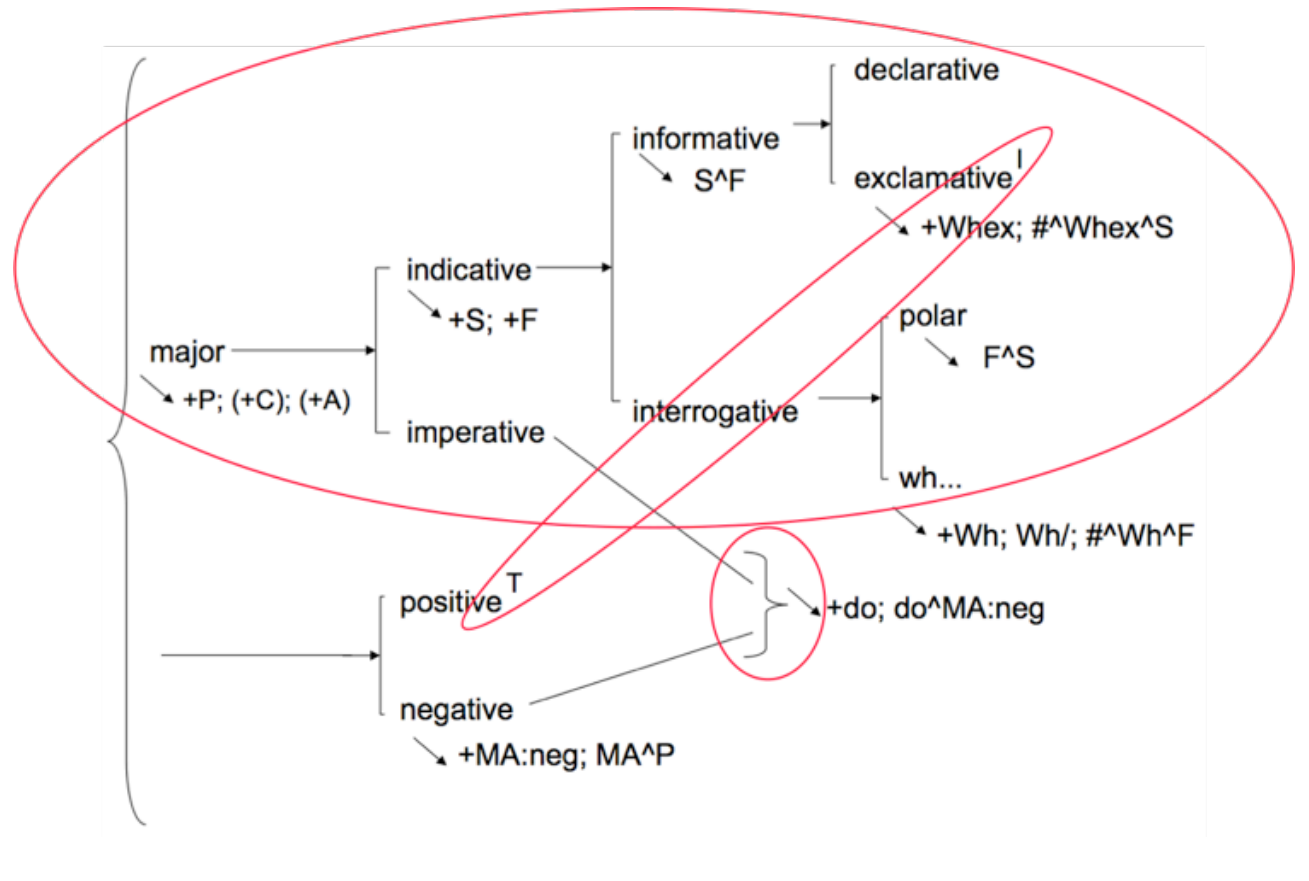

Terms like metafunction in linguistics (or impulse in physics, or semantic density in LCT) are examples of terms for the implication complexes that feature more or less strongly in the technical discourses of the sciences and social sciences. We still have a great deal of work to do exploring the role of symbols, images and artifacts which interact with language in the construal of uncommon sense discourse. Our understanding of field has already been pushed well beyond the initial work on taxonomy and sequencing introduced above, largely through Doran's work on arrays and implication complexing (Doran, 2016). Further work on the multimodal texts enacting disciplinarity is likely to lead to further renovations still.

\subsection{Alter-sensibility (values)}

Let's return now to Flannery's review of Glickson, and take note of another dimension of Flannery's identity, reflecting his climate change activism. He prefaces the quote he subsequently celebrates for its technicality as follows: 
[2'] ...Earth is revealed in all its manifestations: from an oxygen-free infant with toxic oceans and precious little land 3 billions years ago, to an ageing planet destabilized by a plague of bipedal apes. His description of the ocean during the 'greenhouse Earth' episode of 55 million year ago offers a good example of this style:

Elevated $\mathrm{CO}_{2}$ led to acidification of ocean water from $\sim 8.2$ to $\sim 7.5 \mathrm{pH}$ and the extinction of $35-50 \%$ of benthic formaminifera over 1000 years.

This neatly summarizes countless hours of research, and describes an Earth whose atmosphere was so supercharged by greenhouse gases that the acidifying oceans led to mass extinctions, ecosystem crises and an ocean floor corroded red with acid. Only when conditions are reduced to such simple terms can meaningful comparisons between various crises in Earth's history be made (Flannery 2014: 44).

Here the lexical metaphor a plague of bipedal apes enacts Flannery's negative judgment of our species' stewardship of our planet, a coupling he offers to environmentally concerned readers to share. The review continues by appreciating the effects of the plague as one of various planetary crises. This results in an axiologically-charged discourse, condensing the 'feelings, political sensibilities, taste, values, morals, affiliations and so forth' which Maton (2013: 11) describes as one form of semantic density (termed 'axiological-semantic density' and contrasted with 'epistemic-semantic density').

The complementarity of epistemic and axiological condensation is nicely highlighted in the following passage of repartee from a senior secondary history class focusing on what Australians remember as the Vietnam War. One student, David, appears not to be paying attention and his teacher asks him to tell the class about communism.

[4] T (teacher lets out a big breath) Where are we? David, you're sitting there by yourself. You can tell us about communism, OK?

David Don't make me do that. That's against my Christian beliefs.

Students (laugh)

The humour here of course depends on the axiological charging of communism by many sections of Australian society as intolerant of religion. Epistemologically speaking there is of course no necessary opposition between communism and religion, as the Pope's recently welcomed brokering of Cuban and American relations has illustrated. As far as technicality is concerned, communism contrasts with capitalism, not Christianity — with respect to public or private ownership of the means of production. At the same time, axiologically speaking, in neo-liberal discourse communism is loaded with values which colour it as opposed to freedom, democracy, Christianity and so on. Martin (2013a: 29) refers to weakly classified terms such as the '-isms' of history discourse (communism, socialism, nationalism, colonialism 
etc.) as 'flexi-tech' on the basis of the relatively small number of field relations they enter into with comparable terms and the way in which humanities scholars tend to adapt their meaning from text to text according their particular interpretative needs (as documented in Martin \& Matruglio (2013) for Australian secondary school modern history). This perhaps makes such terms especially prone to what Maton (2013) terms 'axiological condensation', especially in politicized discourse-where oppositions such as communism vs religion or socialism vs democracy depend solely on their axiological charge and this charge so often appears to have seriously undermined any epistemological condensation the terms might otherwise afford.

We need to emphasize here however that axiological condensation is part and parcel of every field; even technical terms have value. Consider for example Halliday's 1977 review of ideas about language, which epistemologically contrasts a philosophical-logical tradition with a descriptive-ethnographic one (as summarized in Table 1 ). While most linguists would readily acknowledge the complementarity of these intellectual traditions in the discipline, in their hearts most would align with one orientation or the other-warmly welcoming work fostering the tradition they favour and negatively valuing work in the other. And it is values, not rationality, that matter most when it comes to many spheres of legitimationin relation to appointments, promotions, publications, reviews, conference presentations, honours and so on.

\section{TABLE 1}

Ideas about language (Halliday, 1977)

\section{PHILOSOPHICAL-LOGICAL TRADITION}

DESCRIPTIVE-ETHNOGRAPHIC TRADITION

\begin{tabular}{cc} 
Linguistics as part of philosophy & Linguistics as part of anthropology \\
\hline Grammar as part of logic & Grammar as part of culture \\
\hline Stresses analogy & Stresses anomaly \\
\hline Prescriptive or normative in orientation & Descriptive in orientation \\
\hline Meaning as truth function & Leaning as rhetorical function \\
\hline Language as thought & Language as resource \\
\hline Lormal analysis of sentences & Semantic interpretation of discourse \\
\hline Grammaticality according to rule & Acceptability according to usage \\
\hline High degree of idealization & Lower degree of idealization \\
\hline Decontextualized examples & Real examples \\
\hline Absolutists & Relativists \\
\hline
\end{tabular}


So as far as axiology is concerned, even the technicality of both the formal and functional traditions invokes attitude (Martin \& White, 2005). Maton expands on axiological condensation and charging as follows:

As Bourdieu argues "taste classifies, and it classifies the classifier" (1984: 6): your taste in films, furniture, music, clothes and so forth, say something about you. Similarly, a scholar's choice of theory, citations, writing style, figures, titles, punctuation and so forth, offer messages about what kind of person they are by virtue of the axiologically charged constellation to which those stances are assigned... They show whether your heart is in the right place, your aesthetic, ethical, moral or political affiliations correct, and so whether you are one of us or one of them. In other words, the axiological cosmology generates a hierarchical knower structure, a ranking of actors based on how moral, righteous, virtuous, ethical or politically progressive they are considered to be (Maton, 2014: 163).

From a linguistic perspective this raises the question of how fields accrue values. Recent work on iconization sheds some light on the processes involved from logogenetic (text-time), ontogenetic (life-time) and phylogenetic (evolutionary time) perspectives (Bednarek \& Martin, 2010). Iconization is a process whereby the conceptual meaning of an event or entity is backgrounded and its value to the members of a group is foregrounded-a process whereby ideational meaning is discharged and axiological meaning charged.

We are probably most familiar with this process as it manifests in idioms (Chang, 2004). The phrase cool as a cucumber for example began as a lexical metaphor and over time turned into an idiom judging someone as imperturbable. The expression is now so conventionalized that it doesn't call the salad vegetable to mind. Caple's analysis of image nuclear news stories (2013) describes the way in which images are often used to in effect re-charge the ideational meaning of conventional attitudinal expressions of this kind (as when a image of Belarus soldiers pouring a bucket of cold water over themselves during a Slavic holiday interacts across modalities with the story's title 'Getting the Cold Shoulder').

Iconization is also familiar as it manifests in interpersonal grammatical metaphors, modality metaphors in particular. In the exchange shown in text 5 (from the episodes 'The great game' in the BBC Television series Sherlock), Watson tries to preface a conjecture with an explicitly subjective modality of probability (Has it occurred to you that...). But before he can articulate his thought Holmes interrupts him, taking his modality metaphor as face value as a genuine query about his mental processing. Watson perseveres, taking the sardonic interruption in his stride, to make his point-a point which, as ever, Holmes has already considered. The clever repartee of course depends on Holmes re-charging the ideational meaning (i.e. the mental process occur) of the metaphor Watson intended as charged with interpersonal meaning (i.e. the modality he might have enacted congruently as perhaps).

[5] Watson: You realize we've only stopped for breath since this thing started. Has it occurred to you... 
Holmes: Probably.

Watson: No, has it occurred to you that the bomber's playing a game with you. The envelope. Breaking into the other flat. The dead kid's shoes. It's all meant for you.

Holmes: Yes, I know.

Stenglin, in her work on space grammar (Stenglin, 2008; Martin \& Stenglin, 2007) notes that spaces, artefacts and texts may be supercharged with axiology to the point where they function as bonding icons (bondicons for short) embodying shared values around which fellowships are formed. Among well-known bondicons are the symbols of peace which anchor communities of protest against war (e.g. the semaphore based peace sign designed for the British disarmament movement in 1958 or the dove), alongside inspirational leaders such as Gandhi or Mandela, who embody (among other values) the principles of peaceful protest and forgiveness respectively. Further examples would include the ceremonies, proverbs, slogans, memorable quotations, logos, flags, team colours, coats of arms, mascots and so on that rally communities around shared ideals.

Recently Tann $(2010,2013)$ has developed a valuable framework for thinking about iconization in relation to communal feeling involving the concepts of gemeinschaft, doxa and oracle-where gemeinschaft constructs identities as communities and oppositional categories, doxa constructs identities in terms of communal values around which the communities rally and oracle constructs identities as specific people and things that exemplify the community. In terms of this paper oracles can be thought of as bondicons invoking the shared values (doxa) which affiliate members in communities (gemeinschaft). As far as oracles are concerned, SFL iconography would include its founding guru Halliday, its imagic artifacts (e.g. the cotangential strata in Figure 1 or system network in Figure 6) and well-known 'scripture' (such as the passage on shunting from Halliday, 1961). A more complete picture of SFL iconography is presented in Figure 9. As far as the ‘us and them' of gemeinschaft is concerned, Australianbased SFL is positioned in relation to America's Role and Reference Grammar (Van Valin \& LaPolla, 1997) and the Netherlands's Functional Discourse Grammar (Hengeveld \& Mackenzie, 2008). Two key SFL values are highlighted as doxa: the notion of meaning as choice and functionalism. And three SFL bondicons are presented: a photo of Halliday, the front cover of the 4th edition of his Introduction to Functional Grammar (2014) and the co-tangential circle strata diagram (Martinian articulation). For further exemplification of Tann's model, in the context of restorative justice, see Martin \& Zappavigna (2013).

SFL work on processes of iconization in SFL is still in its infancy. But as Maton's provocation has made clear, there is more to any field than its epistemology. What Maton refers to as 'semantic density' includes axiological condensation as well as epistemological condensation; as Maton (2014b: 66) puts it 'For every knowledge structure there is also a knower structure'. And this brings shared values clearly into the picture. SFL tools for analysing attitude, 


\section{FIGURE 9}

SFL iconography (after Tann, 2013)

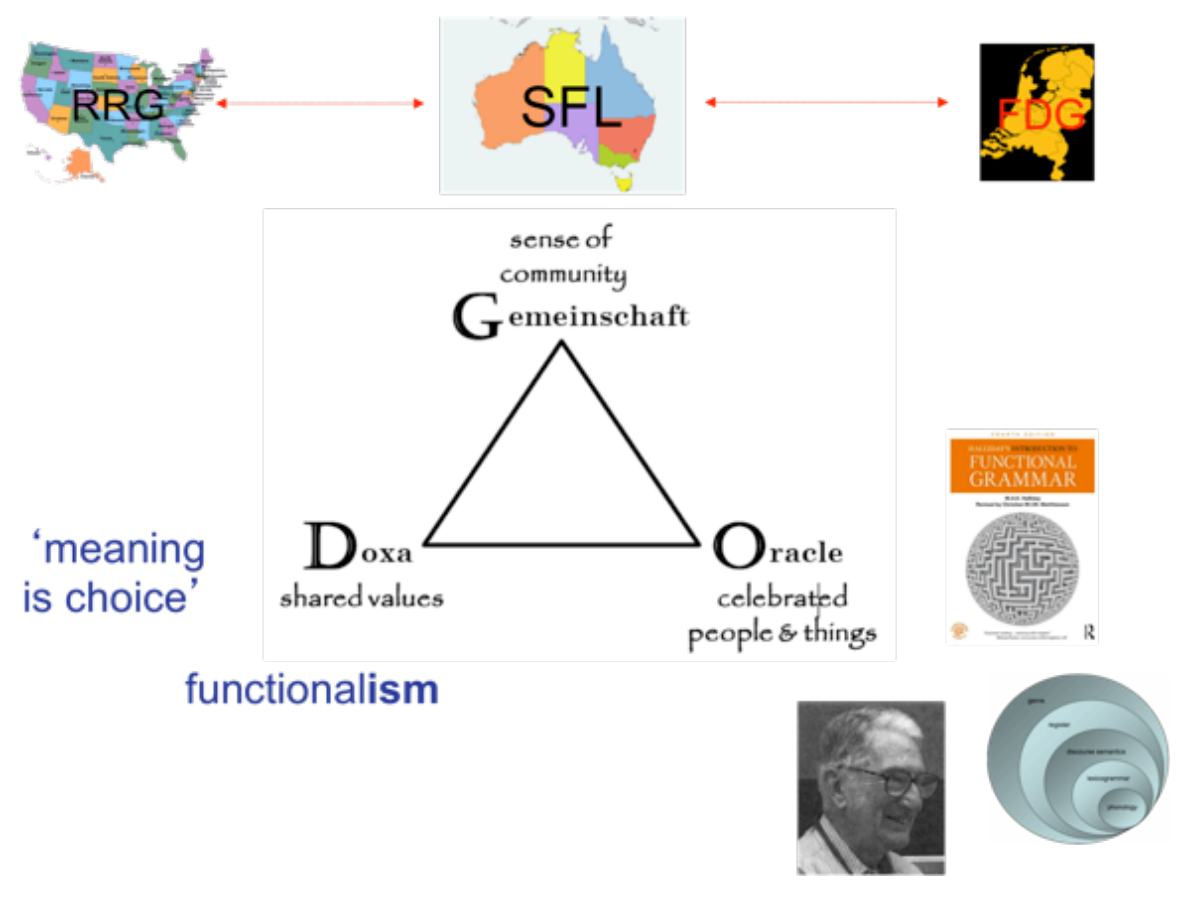

including the attitude invoked by ideational meaning, are by now widely available (based in part on their consolidation in Martin \& White, 2005). But much more work is needed on their role in charging fields axiologically speaking, as texts unfold, as individuals develop and as cultures evolve.

\subsection{Alter-texture (composition)}

We are now in position to return to Flannery's text a third time and consider how he brings his bi-focal gaze, as scientist and activist, to bear on the passage he cites from Glickson. As far as the discourse semantic system of IDENTIFICATION is concerned (Martin \& Rose, 2007), in play here are two instances of text reference ${ }^{3}$ - this and such. The demonstrative this is used to consolidate the quotation as a participant (which as such can summarize research); the comparative such (cf. simple terms like this) likewise consolidates the quotation, this time as a circumstance (the semiotic product of Glickson's labors).

3 I follow here the simplified terminology used in Martin \& Rose (2007); Halliday \& Hasan (1976) use the term 'extended reference' for this phenomenon. 
[3] Elevated $\mathrm{CO}_{2}$ led to acidification of ocean water from $\sim 8.2$ to $\sim 7.5 \mathrm{pH}$ and the extinction of $35-50 \%$ of benthic formaminifera over 1000 years.

This neatly summarizes countless hours of research, and describes an Earth whose atmosphere was so supercharged by greenhouse gases that the acidifying oceans led to mass extinctions, ecosystem crises and an ocean floor corroded red with acid. Only when conditions are reduced to such simple terms can meaningful comparisons between various crises in Earth's history be made (Flannery, T 2014: 44).

As we can see text reference allows writers to construe passages of discourse as semiotic entities and thereby afford their participation in clause grammar. Indefinitely large configurations of meaning can be aggregated in this way. Unlike technicality, which distils configurations of meaning as concepts in a field, text reference aggregates meaning instantially, as a text unfolds. The consolidation of meaning is thus text specific; it does not in itself reconstrue (ideationally) or charge (axiologically) the field. By way of illustrating something of the range of meaning that can be aggregated using text reference consider Text 6 below, where this in the final paragraph consolidates the preceding four paragraphs as a Circumstance of cause ${ }^{4}$.

[6] While Pompeii is one of the most studied of the world's archaeological sites, it has been plagued with serious conservation problems, including poor restoration work, damage from vegetation, pressure from tourism and poor site management.

Much of the restoration work on Pompeii has been done by local firms with no specialized knowledge of restoration techniques. For example the timber roof on the House of Maeger was so poorly designed it could not support the weight of the tiles and collapsed. Poor quality mortar has also been used to protect ancient stonework. Over time this mortar has cracked, allowing water and vegetation to penetrate.

The incursion of uncontrolled weeds has hastened the decay of the ruins. Over 30 different varieties have been identified, including ivy, fennel and fig. As the roots grow they open up further cracks, allowing even more weeds in.

Pompeii's position as an international tourist attraction brings half a million visitors each year. No special walkways for viewing platforms have been constructed, so tourists walk along ancient paths and enter buildings that are not roped off. In some places ancient lead water pipes have been exposed.

There seems to be no overall management plan for the site. Damaged paths and walls have not been repaired, frescoes have not been preserved, and mangy dogs roam the site.

4 The versions of Text 6 used as illustrations here are an emergent factorial explanation based on Lawless et al. (2008: 273-274), an ancient history secondary school textbook (further discussed in Martin, 2013a). 
Available finance has been poorly managed and no proper conservation and interpretation program has been put in place.

As a result of this, the description of Pompeii as a victim of state neglect and indifference and an archaeological catastrophe of the first order is an apt one. Its ongoing destruction since its discovery in the 1590 s has arguably resulted in a greater disaster than its initial destruction by the eruption of Mt Vesuvius one and a half millennia earlier.

PERIODICITY is another resource which can be deployed to aggregate meaning instantially as a text unfolds. The Hyper-Themes for each paragraph in Text 6' below consolidate the elaborating meanings which follow. In 6 ' there is also a Macro-Theme consolidating the meaning of these Hyper-themes and a Macro-New, aggregating the meaning developed in the text as a whole. I have used the symbol '=' below to flag the way in which higher level Theme and New aggregate lower level waves of information.

\section{[6'] Macro-Theme}

While Pompeii is one of the most studied of the world's archaeological sites, it has been affected by poor restoration work, damage from vegetation, pressure from tourism and poor site management.

\section{Hyper-Theme}

Much of the restoration work on Pompeii has been done by local firms with no specialized knowledge of restoration techniques.

$=$

For example the timber roof on the House of Maeger was so poorly designed it could not support the weight of the tiles and collapsed. Poor quality mortar has also been used to protect ancient stonework. Over time this mortar has cracked, allowing water and vegetation to penetrate.

\section{Hyper-Theme}

The incursion of uncontrolled weeds has hastened the decay of the ruins.

$=$

Over 30 different varieties have been identified, including ivy, fennel and fig. As the roots grow they open up further cracks, allowing even more weeds in.

\section{Hyper-Theme}

Pompeii's position as an international tourist attraction brings half a million visitors each year. 
$=$

No special walkways for viewing platforms have been constructed, so tourists walk along ancient paths and enter buildings that are not roped off. In some places ancient lead water pipes have been exposed.

\section{Hyper-Theme}

There seems to be no overall management plan for the site.

$=$

Damaged paths and walls have not been repaired, frescoes have not been preserved, and mangy dogs roam the site. Available finance has been poorly managed and no proper conservation and interpretation program has been put in place.

$=$

\section{Macro-New}

The description of Pompeii as a victim of state neglect and indifference and an archaeological catastrophe of the first order is an apt one. Its ongoing destruction since its discovery in the 1590s has arguably resulted in a greater disaster than its initial destruction by the eruption of Mt Vesuvius one and a half millennia earlier.

Textual aggregation often interacts with ideational and interpersonal resources which both reinforce and take advantage of the scaffolding. Ideationally speaking semiotic nouns may couple with text reference to both name and aggregate a phase of discourse. Flannery uses metadiscourse in this way in Text 6 through the phrase such...terms (with such as text reference and terms as metadiscourse). Text 6 ' is reworked as 6" below which deploys the semiotic noun factor to name the causes of the degeneration of Pompeii as an archaeological site.

\section{[6"]Macro-Theme}

While Pompeii is one of the most studied of the world's archaeological sites, it has been affected by a number of factors, including poor restoration work, damage from vegetation, pressure from tourism and poor site management.

$=$

\section{$[\ldots]$}

$=$

\section{Macro-New}

As a result of these factors, the description of Pompeii as a victim of state neglect and indifference and an archaeological catastrophe of the first order is an apt one. Its ongoing 
destruction since its discovery in the 1590 s has arguably resulted in a greater disaster than its initial destruction by the eruption of Mt Vesuvius one and a half millennia earlier.

Internal conjunction can also be deployed to reinforce the scaffolding composed by high level periodicity. The conjunction finally is used in this way in Text 6"' below to temporally position the final cause canvassed in relation to the presentation of the previous three. The rhetorical effect is to aggregate the first three factors in relation to the fourth.

[6"'] Much of the restoration work on Pompeii has been done by local firms with no specialised knowledge of restoration techniques. For example the timber roof on the House of Maeger was so poorly designed it could not support the weight of the tiles and collapsed. Poor quality mortar has also been used to protect ancient stonework. Over time this mortar has cracked, allowing water and vegetation to penetrate.

A second problem is the incursion of uncontrolled weeds which have hastened the decay of the ruins. Over 30 different varieties have been identified, including ivy, fennel and fig. As the roots grow they open up further cracks, allowing even more weeds in.

Pompeii's position as an international tourist attraction brings half a million visitors each year. No special walkways for viewing platforms have been constructed, so tourists walk along ancient paths and enter buildings that are not roped off. In some places ancient lead water pipes have been exposed.

Finally, there seems to be no overall management plan for the site. Damaged paths and walls have not been repaired, frescoes have not been preserved, and mangy dogs roam the site. Available finance has been poorly managed and no proper conservation and interpretation program has been put in place.

A comparable effect can be achieved through an interaction of text reference and metadiscourse as in 6"' below. There another factor and further factor use comparative reference coupled with metadiscourse to position causes in relation to one another.

[6"''] Much of the restoration work on Pompeii has been done by local firms with no specialized knowledge of restoration techniques. For example the timber roof on the House of Maeger was so poorly designed it could not support the weight of the tiles and collapsed. Poor quality mortar has also been used to protect ancient stonework. Over time this mortar has cracked, allowing water and vegetation to penetrate.

Another factor is the incursion of uncontrolled weeds has hastened the decay of the ruins. Over 30 different varieties have been identified, including ivy, fennel and fig. As the roots grow they open up further cracks, allowing even more weeds in.

A further factor is that Pompeii's position as an international tourist attraction brings half a million visitors each year. No special walkways for viewing platforms have been constructed, so tourists walk along ancient paths and enter buildings that are not roped off. In some places ancient lead water pipes have been exposed. 
Finally, there seems to be no overall management plan for the site. Damaged paths and walls have not been repaired, frescoes have not been preserved, and mangy dogs roam the site. Available finance has been poorly managed and no proper conservation and interpretation program has been put in place.

Interpersonally speaking higher level periodicity can be used to position attitudes in such a way that they prosodically colour elaborating meanings. Inscribed attitude is highlighted in 6"'"' below where it features in the text's Macro-Theme (problem) and Macro-New (neglect, indifference etc.) and one of its Hyper-Themes (problem again), and is explicitly reinforced in three of the elaborations of Hyper-Themes (poorly, poor, careless/y). The overall effect is to accumulate the negative appreciation, turning up the volume as the text unfolds. With or without lower level propagation of this kind the inscription of negative appreciation in higher level Theme and New enacts an interpersonal aggregation of meaning as the prosodic domain of controlling attitude; in rhetorical terms the text provides evidence for and thus justifies the values being charged.

[6"'"'] While Pompeii is one of the most studied of the world's archaeological sites, it has been plagued with serious conservation problems, including poor restoration work, damage from vegetation, pressure from tourism and poor site management.

Much of the restoration work on Pompeii has been done by local firms with no specialized knowledge of restoration techniques.

For example the timber roof on the House of Maeger was so poorly designed it could not support the weight of the tiles and collapsed. Poor quality mortar has also been used to protect ancient stonework. Over time this mortar has cracked, allowing water and vegetation to penetrate.

A second problem is the incursion of uncontrolled weeds which have hastened the decay of the ruins.

Over 30 different varieties have been identified, including ivy, fennel and fig. As the roots grow they open up further cracks, allowing even more weeds in.

Pompeii's position as an international tourist attraction brings half a million visitors each year.

No special walkways for viewing platforms have been constructed, so tourists walk along ancient paths and enter buildings that are not roped off. In some places ancient lead water pipes have been carelessly exposed.

Finally, there seems to be no overall management plan for the site.

Damaged paths and walls have not been repaired, frescoes have not been preserved, and mangy dogs roam the site. Available finance has been poorly 
managed and no proper conservation and interpretation program has been put in place.

As a result of these factors, the description of Pompeii as a victim of state neglect and indifference and an archaeological catastrophe of the first order is an apt one. Its ongoing destruction since its discovery in the 1590 s has arguably resulted in a greater disaster than its initial destruction by the eruption of Mt Vesuvius one and a half millennia earlier.

In spoken discourse, the turn-taking resources of negotiation can also be coupled with metadiscourse (and possibly text reference) to aggregate meaning. This brings the discourse semantic system of NEGOTIATION (dealing with exchange structure) into play (Martin, 1992; Martin \& Rose, 2003, 2007). In the following phase of classroom interaction ${ }^{5}$ the teacher asks for one of the students to read aloud (using the semiotic verb read to nominate the relevant task) and a male student nominates himself (the A2 A 1 A2f exchange below); the student then reads the passage and the teacher acknowledges the service (the A1 A2f exchange below). As we can see the student's Al move performs a linguistic service aggregating a phase of meaning from the relevant text. Extended services of this kind are often found in classroom interaction, typically managed through what Christie (adapting Bernstein) refers to as regulative discourse (Christie, 2002).

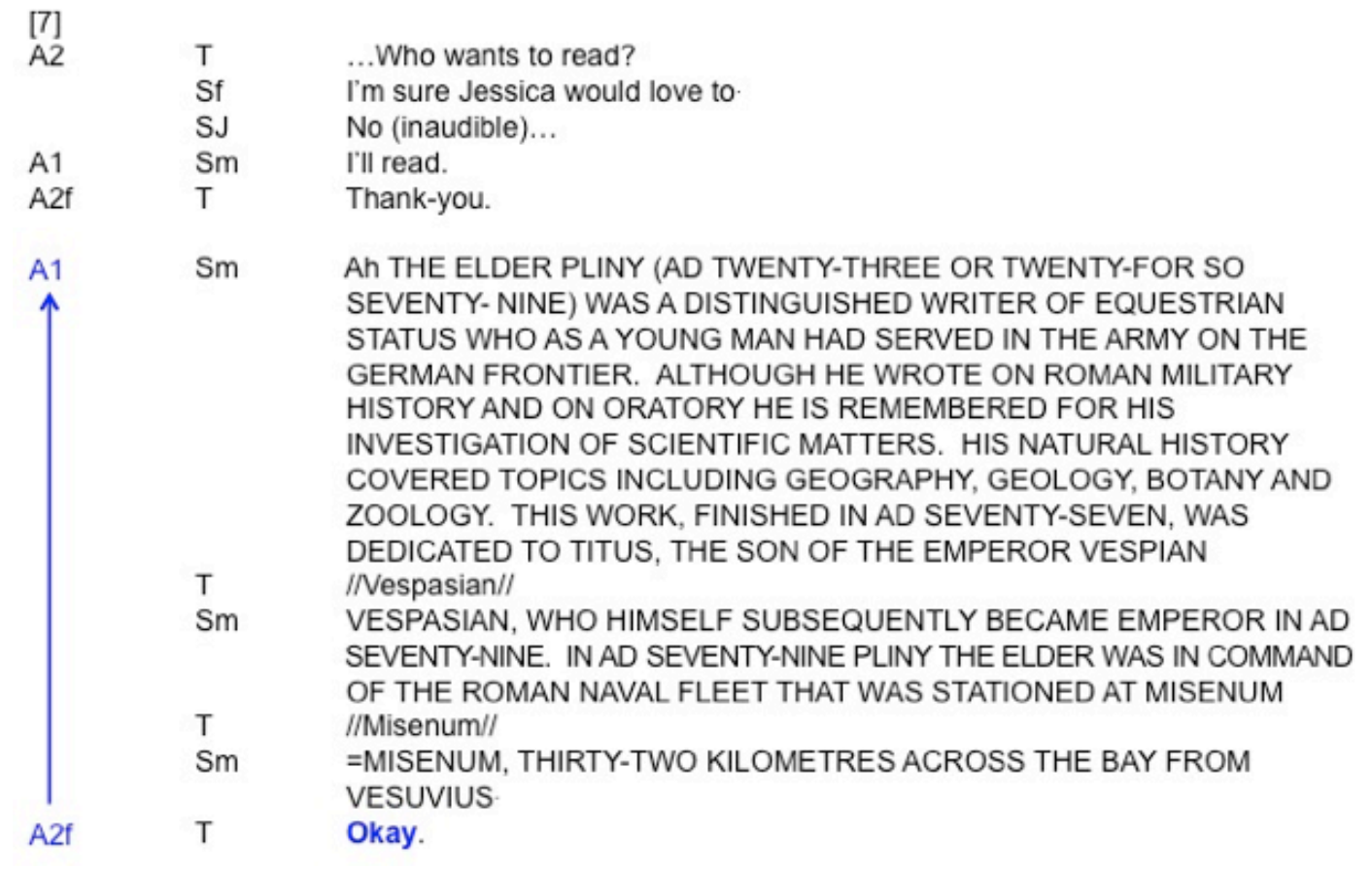

5 To simplify the presentation the tracking and challenging moves in these interactions have not been annotated. 
One final perspective on aggregation we should comment on here involves multimodal texts which combine verbiage and image in synoptic displays of knowledge. Figure 10 illustrates a multimodal assemblage of this kind which deals with the biological implication sequence inflammation. Stages in the process are summarized verbally along the bottom of the text; and the first two stages are specified multimodally - to the left, image and captions detail the infection, vasodilation and phagocyte migration response (in addition providing useful information about the compositional relations involved), and to the right the process of phagocytosis is 'blown up' to illustrate phagocytes (both neutrophils and macrophages) squeezing thought the walls of a dilated blood vessel and engulfing bacteria. Multimodal synopses of this kind highlight the multi-tiered nature of uncommon sense implication sequences, and the uncommon sense classification and composition relations involved. Where well supported by reading and classroom discussion they can work effectively as summative aggregations of accumulated knowledge; where supportive reading and classroom interaction has not taken place they may well function as impenetrable obstacles to teaching/learning. There is certainly nothing transparent about the knowledge structure they encode.

\section{FIGURE 10}

Inflammation processes (Allen \& Greenwood, 2003: 119)

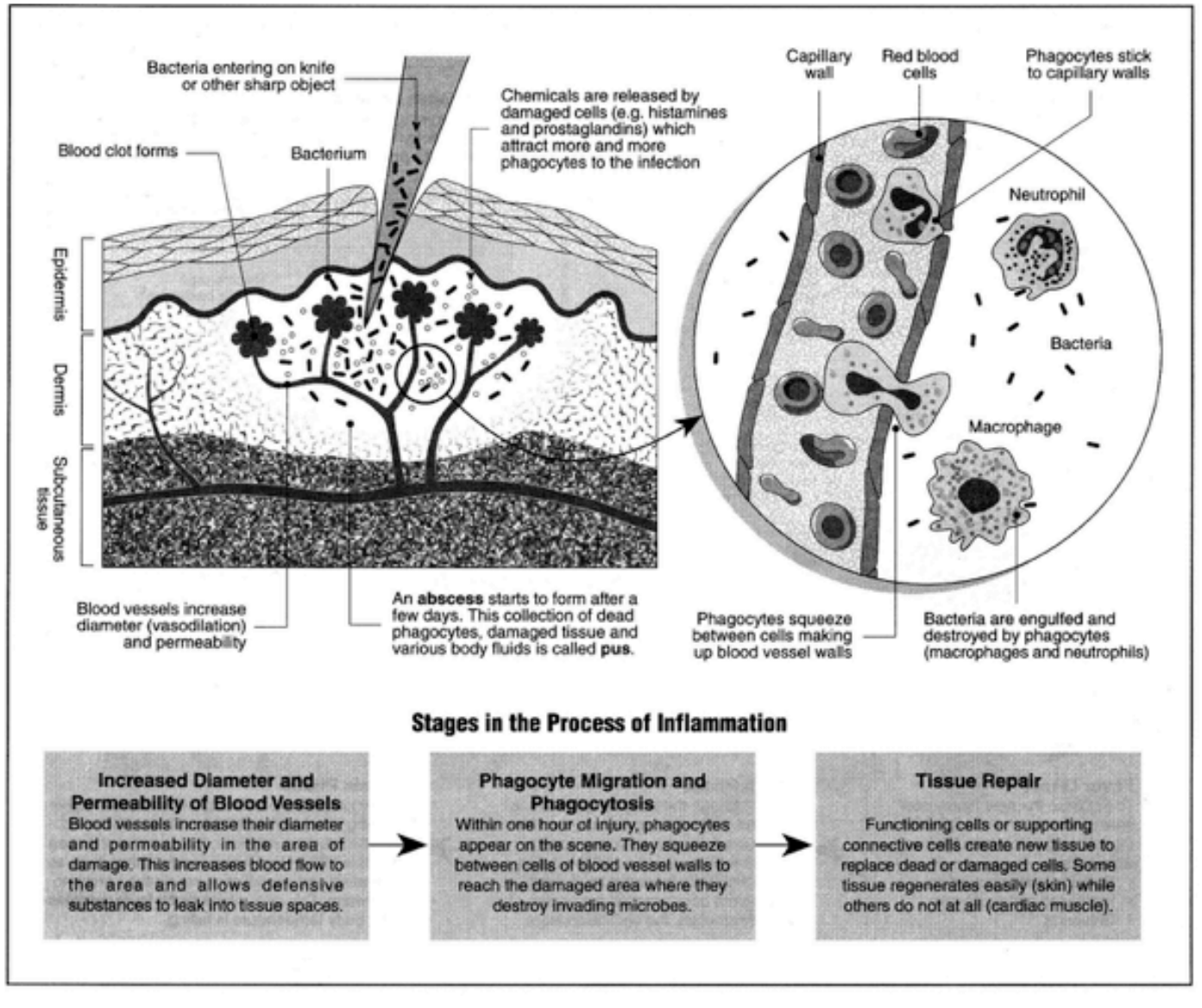




\subsection{Knowledge structure-a metafunctional perspective}

Muller (2007) proposes the notion of 'verticality' to describe how theories progress - via ever more integrative or general propositions (echoing Bernstein's strong/weak internal grammar, 2000: 132-134) or via the introduction of a new language which constructs a 'fresh perspective, a new set of questions, a new set of connections, and an apparently new problematic, and most importantly a new set of speakers' (Bernstein, 2000: 162). And Muller proposes 'grammaticality' to describe how theoretical statements deal with their empirical predicates (echoing Bernstein's strong/weak external grammar; 2000: 132-134). The stronger the (external) grammaticality of a language, the more stably it is able to generate empirical correlates and the more unambiguously because the more restricted the field of referents. In this paper I have tried to give some semiotic substance to these notions by exploring the structure of knowledge metafunctionally, from the perspectives of ideational, interpersonal and textual meaning. From the perspective of ideational meaning, the key variable is technicality - to what degree does the knowledge structure distil meaning as technical terms arranged in field specific taxonomies, arrays, sequences and complexes. From the perspective of interpersonal meaning the key variable is iconization - to what degree does the knowledge structure charge meaning with values legitimising participation in a community of practice. From the perspective of textual meaning the key variable is aggregation-to what degree does a text consolidate meaning, prospectively or retrospectively, as it unfolds.

Taken together, technicality, iconization and aggregation might be grouped together in SFL under the cover term mass. This avoids confusing SFL and LCT by deploying Maton's term 'semantic density' in two distinct theories with different disciplinary affiliations and different knowledge-knower structures. The range of meanings which have been proposed here for the term mass means care must be taken to clarify what variables are being considered whenever the term is used. The number of variables considered will of course depend on the problem being addressed. A study of the transition from home to school, and thus from common to uncommon sense, might well focus on variables associated with technicality. A study of the demands of academic literacy in secondary school would need to add a focus on aggregation to the picture, as managing concentrations of technicality in reading and writing becomes a focal challenge for so many students. A study of the discourses of the humanities would have to deal carefully with iconization and the sensibilities assumed when interpreting the past (in history), literature (in English) or performances (in Creative Arts). Selecting tools on the basis of a problem is the key.

\section{Mass and presence}

As noted in section 1, SFL/LCT dialogue around the question of cumulative knowledge-building in secondary school prompted the re-appraisal of work on field in SFL undertaken here. In this paper I have responded to Maton's concept of 'semantic density' from a linguistic pers- 
pective by factoring knowledge structure metafunctionally_giving rise to ideational (technicality), interpersonal (iconicity) and textual (aggregation) orientations to mass.

Alongside semantic density Maton proposes 'semantic gravity' as a complementary factor of the LCT dimension named 'Semantics' (2014: 110):

One can thus conceptualize practices in terms of the degree to which meaning relates to its context. This semantic gravity may be relatively stronger or weaker along a continuum. When semantic gravity is stronger, meaning is more closely related to its social or symbolic context of acquisition or use; when it is weaker, meaning is less dependent on its context. One can also describe processes of strengthening semantic gravity, such as moving from abstract or generalized ideas towards concrete and delimited cases, and weakening semantic gravity, such as moving from the concrete particulars of a specific case towards generalizations and abstractions whose meanings are less dependent on that context.

Maton's allusion to 'contextual dependency' naturally invited a response from functional linguists who have theorized comparable terminology for some decades in relation to the register variable mode. Martin \& Matruglio (2013) have responded to this challenge by factoring context dependency metafunctionally_ giving rise to ideational (iconicity), interpersonal (negotiability) and textual (implicitness) orientations to what he terms presence. This factoring is summarized in Table 2 below, which in addition considers the kind of presence typically associated with academic discourse-where 'anti-gravity' resources couple in a syndrome of explicitness, factuality and abstraction.

\section{TABLE 2}

Types of presence in relation to academic discourse

\begin{tabular}{ccc} 
METAFUNCTION & TYPE OF PRESENCE & ACADEMIC DISCOURSE \\
\hline textual & implicitness & explicitness \\
\hline interpersonal & negotiability & factuality \\
\hline ideational & iconicity & abstraction \\
\hline
\end{tabular}

Here I have tried to complement this reconceptualization of context dependency in SFL in relation to a reconsideration of disciplinarity. Table 3 summarizes the metafunctional factoring of mass aggregation, iconization and technicality introduced in this paper, and in addition considers the kind of mass associated with academic discourse-where uncommon sense resources amass meaning in a syndrome of integration, radiation and condensation.

Maton (2016: 16) portrays a 'semantic plane' (see Figure 7 of Martin and Maton, Chapter 1, this volume): a topology intersecting the concepts of semantic density and semantic gra- 


\section{TABLE 3}

Types of mass in relation to academic discourse

\begin{tabular}{ccc} 
METAFUNCTION & TYPE OF MASS & ACADEMIC DISCOURSE \\
\hline textual & aggregation & integration \\
\hline interpersonal & iconization & radiation \\
\hline ideational & technicality & condensation \\
\hline
\end{tabular}

vity to map semantic codes and position four principal modalities which form the basis of achievement or status in social practices. Inspired by his mapping, I have intersected mass and presence in Figure 11 below by way of mapping disciplinarity in terms of the syndromes of meaning characterising their knowledge-knower structures. The vertical axis orders disciplinarity with respect to degrees of presence; the horizontal axis orders disciplinarity with respect to degrees of mass. The topology thus idealizes (i) the humanities as proto-typically interpretive discourse (-presence, -mass) in relation to its relatively weakly classified technicality, high degree of abstraction and invoked values; (ii) science as prototypically technical discourse (-presence, +mass) in relation to its relatively strongly classified condensed conceptualizations and high degree of abstraction, factuality and explicitness; (iii) trades, crafts etc. as proto-typically specialized discourse (+presence, +mass) in relation to their relatively complex technicality and hands-on 'here and now' practices; and (iv) domestic activity as prototypically everyday discourse (+presence, - mass) in relation to its relatively simple segmental taxonomies and sequences learned ostensively by doing with.

In simpler terms Figure 11 idealizes discourses featuring alter-sensibility (the humanities), alter-reality (science), extended reality (trades, crafts etc.) and common sense (everyday practices). Note however that the axes in our typology are clines, and that discourses or individual texts can be positioned anywhere along the clines in this two-dimensional metaphoric space. Note in addition that Figure 11 radically simplifies the outlines of mass and presence in Tables 2 and 3; the topology is potentially multidimensional, since both mass and presence can each be factored metafunctionally as three axes ${ }^{6}$ not one. Note in this regard that for Figure 11 I have concentrated on the epistemological dimension of mass (technicality and aggregation), setting aside axiology (iconization). I will not pursue the more delicate mapping of knowledge structures afforded by this factoring here.

6 The weight given to one or another metafunction in such factoring would also be a critical variable; for example, if we made iconization critical as far as mass was concerned we might well reverse the position of science (-iconization for alter-reality) and humanities (+iconization for alter-sensibility) in the topology. 


\section{FIGURE 11}

Mapping knowledge structures (presence by mass)

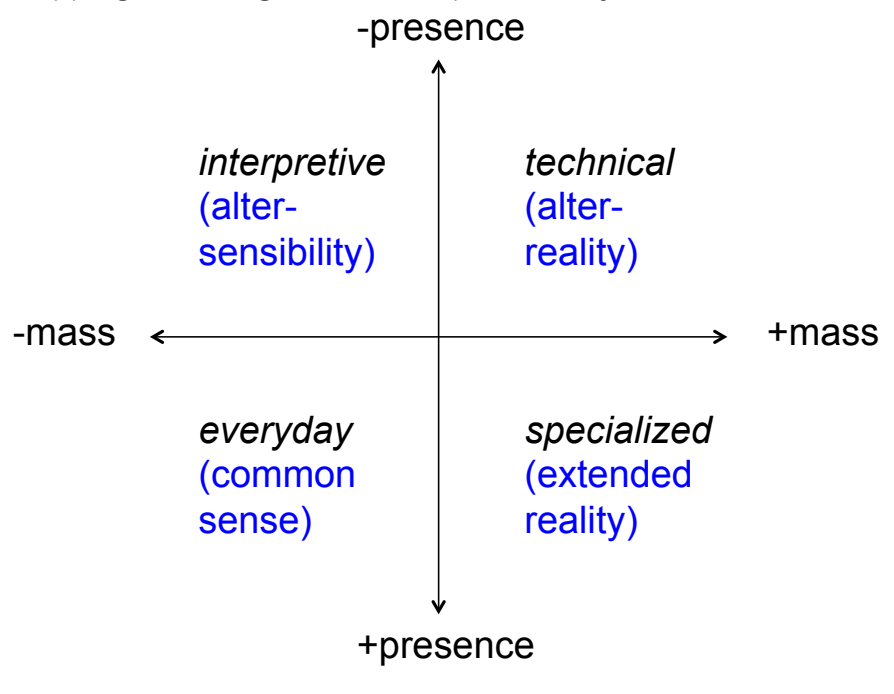

As I noted when responding in Martin \& Matruglio (2013) to Maton's work on semantic gravity (2009, 2011, 2013, 2014b), interdisciplinarity at its most productive encourages disciplines to interrogate their own knowledge-knower structure, and adjust and expand it as required. SFL and code sociology have impacted on one another in these terms many times over the course of cooperative research since Halliday and Bernstein's initial collaborations in Britain in the 1960s (see Martin, 2011; Maton \& Doran, 2016). Responding to Maton's semantic gravity and semantic density I have had to return to the register variables mode and field, and reconsider the picture of meanings at risk outlined in Figure 1 -where mode is positioned as by and large composed by textual meanings and field by and large construed by ideational ones. Maton's challenge has led me to rework our understanding of both context dependency and disciplinarity from the perspective of all three metafunctions not just one. And this of course calls into question the traditional association of context dependency with mode and disciplinarity with field in SFL's realization hierarchy.

I would probably be the last systemicist to set aside the insights afforded by Halliday's association of metafunctions with register variables. As outlined in Martin (2014), one of the primary reasons for proposing a stratified model of context was to strengthen the field/ideational meaning, tenor/interpersonal meaning and mode/textual meaning hook-up Halliday proposed. The predicted correlations have never been properly explored, mainly because of the difficulty we face analysing the discourse semantics of the big data required. This is simply a technological issue and it is far too early to abandon Halliday's vision now.

In the meantime, we need to position cross-functional concepts such as presence and mass in our model, in order to foster work on these syndromes of meaning-whether focusing on big data or small. The natural place to escape the tyranny of metafunctions in 
current SFL theory is the hierarchy of instantiation, where meanings couple across systems as a text unfolds (Martin, 2010). Along this hierarchy it doesn't matter whether the couplings draw on meanings from different ranks, strata or metafunctions (or different modalities or even languages for that matter). The challenge is to show how choices from system integrate in a apparently seamless unfolding text. Exploring syndromes of meaning such as presence and mass which cut across metafunctions is a natural part of studies of this kind, and can lead productively to understandings of context dependency and disciplinarity not afforded by the realizational association of textual meaning with mode and ideational meaning with field.

Let me end with just one illustration of this point. If our studies of field are limited to ideational meaning, what can we say about the values associated with knowledge-knower structure in any discipline? To study values we have to consider attitude and this means bringing the interpersonal resources of appraisal into the picture and asking how they are coupled with ideation in a discipline and by whom. No discipline relies on epistemology alone. I expect that our negative characterization of the humanities in terms of a relative absence of technicality is predicated on just this limitation. We haven't arrived at a productive characterization of its alter-sensibility and its role in academe and beyond precisely because the questions we've been asking about disciplines have been too ideational. We need the perspective afforded by instantiation alongside that of realization in this regard, and so see field as one dimension of disciplinarity, not the whole story. As Maton (2014b) highlights, every social practice involves both knowledge and knowers; and we are much indebted to him in SFL for reminding us that knowers and their values are a critical dimension of knowledgebuilding in social practices of every kind.

\section{Bibliographic references}

Allen, R. \& T. Greenwood, 2012: Year 12 Biology 2003, Hamilton, NZ: Biozone Learning Media Ltd, New Zealand (updated annually).

Bednarek, M. \& J. R. Martin (eds.), 2010: New Discourse on Language: functional perspectives on multimodality, identity and affiliation, London: Continuum.

Bernsteln, B., 2000: Pedagogy, Symbolic Control and Identity: Theory, research, critique, London: Rowman \& Littlefield.

ButLer, C. S., 2003: Structure and Function: A guide to three major structural-functional theories, Amsterdam: Benjamins.

CAPLE, H., 2013: Photojournalism: a social semiotic approach, London: Palgrave McMillan. 
Chang, C., 2004: English Idioms and Interpersonal Meaning, Guangzhou: Sun Yat Sen University Press.

Christie, F., 2002: Classroom Discourse Analysis, London: Continuum.

Christie, F. \& J. R. Martin (eds.), 1997: Genre and Institutions: social processes in the workplace and school, London: Cassell (Open Linguistics Series).

Christie, F \& J. R. Martin (eds.), 2007: Language, Knowledge and Pedagogy: functional linguistic and sociological perspectives, London: Continuum.

Christie, F. \& K Maton (eds.), 2011: Disciplinarity: functional linguistic and sociological perspectives, London: Continuum.

Doran, Y. J., 2016: Multisemiosis in Physics: Building Knowledge through Mathematics and its Interaction with Language and Image, Unpublished PhD Dissertation, Department of Linguistics, The University of Sydney.

Flannery, T., 2014: "The last of their kind: Tim Flannery on Andrew Glickson's Evolution of the Atmosphere", The Monthly, March 2014, 44-47.

Halliday, M. A. K., 1961: "Categories of the theory of grammar", Word 17(3), 241-292 [reprinted in G. Kress (ed.), 1976: Halliday: System and Function in Language, Oxford University Press]. Halliday, M. A. K., 1969: "Options and Functions in the English Clause”, Brno Studies in English 8, 81-88.

Halliday, M. A. K., 1977: "Ideas about language” in M. A. K. Halliday, Aims and Perspectives in Linguistics, Applied Linguistics Association of Australia (Occasional Papers 1), 32-49.

HallidAY, M. A. K., 2003: The Language of Early Childhood, volume 4 in The Collected Works of M A K Halliday, edited by Jonathan Webster, London: Continuum.

Halliday, M. A. K., 2004: The Language of Science, volume 5 in the Collected Works of M. A. K. Halliday, edited by Jonathan Webster, London: Continuum.

Halliday, M. A. K., 2014: Halliday's Introduction to Functional Grammar, fourth edition [revised by C. M. I. M. MatThiessen], London: Routledge.

Halliday M. A. K. \& R. Hasan, 1976: Cohesion in English, London: Longman.

HallidaY, M. A. K. \& J. R. Martin, 1993: Writing Science: literacy and discursive power, London: Falmer.

Hengeveld, K. \& L. Mackenzie, 2008: Functional Discourse Grammar, Oxford: Oxford University Press.

Lawless, J., K. Cameron \& C. Young, 2008: Unlocking the past: preliminary studies in the ancient world, second edition, Melbourne: Nelson. 
MARTIN, J. R., 1990: "Literacy in science: learning to handle text as technology" in F. Christie (ed.): Literacy for a Changing World, Melbourne: Australian Council for Educational Research (Fresh Look at the Basics), 79-117.

MARTIN, J. R., 1989: "Technicality and abstraction: language for the creation of specialised texts" in F. Christie (ed.): Writing in Schools: reader, Geelong, Vic.: Deakin University Press, 36-44. MARTIN, J. R., 1992: English Text: system and structure, Amsterdam: Benjamins.

MARTIN, J. R., 2007: "Genre and field: social processes and knowledge structures in systemic functional semiotics" in L. Barbara \& T. Berber Sardinha (eds.): Proceedings of the 33rd International Systemic Functional Congress, São Paulo: PUCSP, 1-35 [available at http://www.pucsp. br/isfc].

MARTIN, J. R. 2010: "Semantic variation: modelling system, text and affiliation in social semiosis” in M. Bednarek \& J. R. Martin (eds.): New Discourse on Language: functional perspectives on multimodality, identity and affiliation, London: Continuum, 1-34.

MARTIN, J. R., 2011: "Bridging troubled waters: interdisciplinarity and what makes it stick" in F. Christie \& K. Maton (eds.): Disciplinarity: functional linguistic and sociological perspectives, London: Continuum, 35-61.

Martin, J. R., 2012: Register Studies, volume 4 in Collected Works of J. R. Martin (ed.: W. ZhenhuA), Shanghai: Shanghai Jiao Tong University Press.

MARTIN, J. R., 2013a: "Embedded literacy: knowledge as meaning”, Linguistics and Education 24 (1), 23-37.

MARTIN, J. R., 2013b: Systemic Functional Grammar: a next step into the theory - axial relations (Chinese translation and extensions by WANG Pin \& ZHU Yongsheng). Beijing: Higher Education Press.

Martin, J. R., 2014: "Evolving Systemic Functional Linguistics: beyond the clause”, Functional Linguistics, 1(3) [available at https://functionallinguistics.springeropen.com/ articles/10.1186/2196-419X-1-3].

Martin, J. R. \& K. Maton (eds.): 2013: Cumulative knowledge-building in secondary schooling, special issue of Linguistics and Education 24(1).

Martin, J. R. \& E. Matruglio, 2013: "Revisiting mode: context in/dependency in Ancient History classroom discourse", Studies in Functional Linguistics and Discourse Analysis 5, 72 -95 [revised for Spanish translation by B. Quiroz as "Retorno al modo: in/dependencia contextual en el discurso de las clases de historia antigua”, Onomázein 2014 (número especial IX ALSFAL, 186-213)].

Martin, J. R., K. Maton \& E. Matruglio, 2010: "Historical cosmologies: epistemology and axiology in Australian secondary school history”, Revista Signos 43(74), 433-463.

MARTIN, J. R. \& D. Rose, 2003: Working with Discourse: meaning beyond the clause, first edition, London: Continuum. 
Martin, J. R. \& D. Rose, 2007: Working with Discourse: meaning beyond the clause, second edition, London: Continuum.

MARTIN, J. R. \& D. Rose, 2008: Genre Relations: mapping culture, London: Equinox.

MARTIN, J. R. \& M. Stenglin, 2007: "Materialising reconciliation: negotiating difference in a postcolonial exhibition" in T. Royce \& W. Bowcher (eds.): New Directions in the Analysis of Multimodal Discourse, Lawrence Erlbaum Associates: Mahwah, New Jersey, 215-238.

MARTIN, J. R. \& R. VEEL, 1998: Reading Science: critical and functional perspectives on discourses of science, London: Routledge.

Martin, J. R. \& P. R. R. White, 2005: The Language of Evaluation: appraisal in English. London: Palgrave.

Martin, J. R. \& M. Zappavigna, 2013: "Youth Justice Conferencing: ceremonial redress", International Journal of Law, Language and Discourse 3(2) 2013, 103-142.

Martin, J. R., M. Zappaviga, P. Dwyer \& C. Cleirigh, 2013: "Users in uses of language: embodied identity in Youth Justice Conferencing", Text \& Talk 33(4/5), 467-496.

Maton, K., 2009: "Cumulative and segmented learning: Exploring the role of curriculum structures in knowledge-building”, British Journal of Sociology of Education 30(1), 43-57.

Maton, K., 2011: "Theories and things: The semantics of disciplinarity" in F. Christie \& K. Maton (eds.): Disciplinarity: Functional linguistic and sociological perspectives, London: Continuum, 62-84.

Maton, K., 2013: “Making semantic waves: A key to cumulative knowledge-building”, Linguistics and Education 24(1), 8-22.

Maton, K., 2014a: "Building powerful knowledge: The significance of semantic waves" in B. BARRETT \& E. RATA (eds.): Knowledge and the Future of the Curriculum, London: Palgrave Macmillan, 181-197.

Maton, K., 2014b: Knowledge and Knowers: Towards a realist sociology of education, London: Routledge.

Maton, K., 2016: “Legitimation Code Theory: Building knowledge about knowledge-building” in K. Maton, S. Hood \& S. Shay (eds.): Knowledge-building: Educational studies in Legitimation Code Theory, London: Routledge, 1-24.

Maton, K., S. Hood \& S. Shay (eds.), 2016: Knowledge-building: Educational studies in Legitimation Code Theory, London: Routledge.

MULleR, J., 2007: “On splitting hairs: Hierarchy, knowledge and the school curriculum” in F. CHRISTIE \& J. R. MARtin (eds.): Language, Knowledge and Pedagogy, Continuum, London, 65-86. 
Ormerod, J., 1981: Sunshine, London: Frances Lincoln Children's Books.

Painter, C., 1984: Into the Mother Tongue: a case study of early language development, London: Pinter.

PaInTER, C., 1999: Learning through Language in Early Childhood, London: Cassell.

Painter, C., 2003: "Developing attitude: an ontogenetic perspective on APPRAISAL", Text 23(2), 183210.

Rose, D., D. McInnes \& H. KöRneR, 1992: Scientific Literacy (Write it Right Literacy in Industry Research Project-Stage 1), Sydney: Metropolitan East Disadvantaged Schools Program.

Scott, L. \& S. Robinson, 1993: Australian Journey: environments and communities, Melbourne: Longman.

Stenglin, M., 2008: "Olympism: how a Bonding icon gets its 'charge"' in L. Unsworth (ed.): Multimodal Semiotics: Functional Analysis in the Contexts of Education, London: Continuum, 50-66.

TANN, K. 2010a: "Imagining communities: a multifunctional approach to identity management in texts" in M. Bednarek \& J. R. Martin (eds.): New Discourse on Language: functional perspectives on multimodality, identity and affiliation, London: Continuum, 163-194.

TANN, K., 2010b: Semogenesis of a Nation: An Iconography of Japanese Identity. Unpublished PhD Dissertation, University of Sydney, Australia.

TANN, K., 2012: "The language of identity discourse: introducing a framework for functional iconography", Linguistics and the Human Sciences 8(3), 361-391.

UnSWORTH, L., 1997a: "Scaffolding reading of science explanations: accessing the grammatical and visual forms of specialised knowledge", Reading 31(3), 30-42.

UnSWORTH, L., 1997b: "Explaining explanations: enhancing scientific learning and literacy development”, Australian Science Teachers Journal 43(1), 34-49.

UnsworTH, L., 1997C: "Sound' explanations in school science: a functional linguistics perspective on effective apprenticing texts", Linguistics and Education 9(2), 199-226.

Van Valin, R. D. \& R. LaPolla, 1997: Syntax: Structure, meaning, and function, Cambridge: Cambridge University Press.

VeEL, R., 1992: "Engaging with scientific language: a functional approach to the language of school science", Australian Science Teachers Journal 38(4), 31-35.

WhITE, P., 1998: "Extended Reality, Proto-Nouns and the Vernacular: distinguishing the technological from the scientific" in J. R. MARTIN \& R. VeEL (eds.): Reading Science: critical and functional perspectives on discourses of science, London: Routledge, 266-296. 
WignelL, P., 2007: On the Discourse of Social Science, Darwin: Charles Darwin University Press.

Wignell, P., J. R. Martin \& S. EgGins, 1990: "The discourse of geography: ordering and explaining the experiential world", Linguistics and Education 1(4), 359-392. 